\title{
Oral inflammatory diseases and systemic inflammation: role of the macrophage
}

\section{Hatice Hasturk *, Alpdogan Kantarci and Thomas E. Van Dyke}

Department of Periodontology, The Forsyth Institute, Cambridge, MA, USA

Edited by:

Amiram Ariel, University of Haifa,

Israel

\section{Reviewed by:}

Manuela Mengozzi, Brighton and

Sussex Medical School, UK

Gerard L. Bannenberg, Solutex, Spain

\section{${ }^{*}$ Correspondence:}

Hatice Hasturk, Department of Periodontology, The Forsyth Institute,

245 First Street, 17th Floor,

Cambridge, MA 02142, USA.

e-mail: hhasturk@forsyth.org
Inflammation is a complex reaction to injurious agents and includes vascular responses, migration, and activation of leukocytes. Inflammation starts with an acute reaction, which evolves into a chronic phase if allowed to persist unresolved. Acute inflammation is a rapid process characterized by fluid exudation and emigration of leukocytes, primarily neutrophils, whereas chronic inflammation extends over a longer time and is associated with lymphocyte and macrophage infiltration, blood vessel proliferation, and fibrosis. Inflammation is terminated when the invader is eliminated, and the secreted mediators are removed; however, many factors modify the course and morphologic appearance as well as the termination pattern and duration of inflammation. Chronic inflammatory illnesses such as diabetes, arthritis, and heart disease are now seen as problems that might have an impact on the periodontium. Reciprocal effects of periodontal diseases are potential factors modifying severity in the progression of systemic inflammatory diseases. Macrophages are key cells for the inflammatory processes as regulators directing inflammation to chronic pathological changes or resolution with no damage or scar tissue formation. As such, macrophages are involved in a remarkably diverse array of homeostatic processes of vital importance to the host. In addition to their critical role in immunity, macrophages are also widely recognized as ubiquitous mediators of cellular turnover and maintenance of extracelIular matrix homeostasis. In this review, our objective is to identify macrophage-mediated events central to the inflammatory basis of chronic diseases, with an emphasis on how control of macrophage function can be used to prevent or treat harmful outcomes linked to uncontrolled inflammation.

Keywords: innate immune system, macrophage, oral disease, inflammation, resolution

\section{INTRODUCTION}

Inflammation is the physiological response of the body to injury. The inflammatory response can be either acute and of short duration or chronic, which does not resolve and leads to pathology. The major function of innate immune cells most studied during the inflammatory process is the identification and recognition of the injurious and/or foreign substances promoting the defense response. Less acknowledged roles played by the innate immune cells involve the resolution pathways and wound healing, both of which include repair and regeneration of lost or damaged tissues. These are now recognized as highly regulated, active processes rather than passive events (Van Dyke, 2008). Macrophages are actively involved in all phases of inflammation and their role as effector and regulatory cells is now widely recognized. Another interesting and important feature of macrophages is their high level of specialization and tissue specificity. While all tissue-bound macrophages differentiate from circulating monocytes, they acquire distinct characteristics and functions locally due to their response profiles. One of the major factors for this diversity is the complexity of microbial load as well as tissue architecture. Thus, it is no surprise that some of the most sophisticated interactions between the host and parasites also dictate the most evolved phenotypic characteristics of the macrophage. Some examples of this specificity and complexity of macrophage phenotype and function are the Kupffer cells of the liver and macrophages of the lung alveoli where the cells, while similar in appearance, are involved in distinct responses against different pathogens as well as non-pathogenic stimuli.

The oral cavity is one of the most ecologically complex microenvironments in the human body where interactions between the host and microbes define health and disease (Gemmell et al., 1997). The teeth are the only functional hard tissues extending from inside to outside of the human body crossing a series of other hard (i.e., bone) and soft (i.e., connective tissue and epithelia) tissues surrounded by a tight biofilm formed by the richest collection of bacteria outside the colon. Such architecture creates several zones, which work in concert during the inflammatory responses in the mouth. Regulation of immuneinflammatory mechanisms in oral disease is governed in part by patient susceptibility and environmental factors (Seymour, 1991; Seymour and Gemmell, 2001; Uitto et al., 2003). In particular; oral macrophages address these complex requirements for mounting a successful inflammatory response as the cell type at the center of many processes including signaling to resolution of inflammation, healing, and regeneration. In this review, within the context of pathogenic mechanisms, possible clinical outcomes will be 
discussed in relation to the inflammatory-immunological changes throughout the disease process. Since most inflammatory diseases of the oral cavity involve the tissues of periodontium, the pathological changes in the periodontal structure will be used as a model to assess the role of the macrophages in oral inflammation and its resolution.

\section{ACTIVATION OF ORAL INFLAMMATION AND THE ROLE OF MACROPHAGES}

Typically, there are two common diseases affecting the oral tissues and the health of the supporting structures of a tooth. In the case of gingivitis, inflammation is limited to the soft tissues, epithelium, and connective tissue; or in the case of periodontitis, inflammatory processes extend to the supporting tissues including the alveolar bone (Page and Schroeder, 1976). In both forms of periodontal inflammation, the pathological consequences are associated with the accumulation of bacteria at the tooth surface leading to a host response generating inflammatory cell infiltration (Socransky and Haffajee, 2005). Since the soft and hard tissues of the oral cavity are part of the same functional and physiological organ, separating the host response to several components is artificial and does not acknowledge the dynamic relationship between the cells, bacteria, and extracellular structures. Likewise, while practical and instructive, the supposition of a linear shift in lesions from acute to chronic is not clear. Recent discoveries defining the pathways of resolution in the inflammatory processes challenge the concepts of compartmentalization and linearity in acute and chronic responses (Serhan, 2010; Pruss et al., 2011). Nevertheless, this is the prevailing paradigm, since the tools for analyses of the events at multiple levels are just being incorporated into oral research (Singh et al., 2011; Hasturk et al., 2012). Based on the preliminary results of studies that use high-throughput measurements to generate a systems-biology approach, the complex nature of host-bacteria interactions in a highly complex environment of the oral cavity is being redefined (Bakthavatchalu et al., 2011; Mishima and Sharma, 2011; Singh et al., 2011). To this end, novel approaches have revealed the orchestrated coupling of activation and resolution phases as well as tissue healing.

Macrophages are central to the coordinated resolution of inflammation and return to tissue homeostasis (Zadeh et al., 1999). During the first step of the inflammatory process directed against microorganisms, bacteria, and their virulence factors (e.g., capsule, lipopolysaccharide, fimbria) trigger receptor-mediated production of cytokines by epithelial cells with simultaneous release of neuropeptides, which cause vasodilation of local blood vessels. Generation of chemoattractant proteins (chemokines) at this stage results in attraction of the first line of defense, the neutrophil, which leave the vessels and migrate to the site of microbial invasion. This step is critical and plays a pivotal role in generation of an effective defense system. Neutrophils are followed by the macrophages. This is the step usually where clinical signs of oral inflammation including bleeding, swelling, and redness of the gingiva are detectable. The inflection can either be confined and cleared by the function of neutrophils and macrophages at this early stage, or expand to include the other cells and structures (Page and Schroeder, 1976). Being myeloid cells of hematopoietic origin (Medzhitov and Janeway, 1997; Janeway and Medzhitov,
2002) the overall role of the macrophages is to limit the pathological changes to the soft tissues or elevate the inflammatory response to the next level. Major functions of macrophages include elimination of invading bacteria, recruitment of other cells to the site of infection, clearance of the excess neutrophils, production of cytokines and chemokines, and activation of the lymphocytemediated adaptive immune response. The net outcome of these functions can be either complete resolution with healing, limiting the infection with resultant fibrosis and healing with scar tissue formation, or a failure to clear the infection with establishment of a chronic inflammatory lesion.

In the case that the inflammatory process is prolonged and becomes chronic, destruction of soft and hard tissues including the alveolar bone is observed due to direct tissue destruction mediated by inflammation (McCauley and Nohutcu, 2002; Hasturk et al., 2006; Taubman et al., 2007; Graves, 2008; Li et al., 2011). Macrophages together with neutrophils are responsible of phagocytosis and digestion of microorganisms and foreign substances through surface receptors that recognize and bind certain surface molecules of bacteria such as the lipopolysaccharides (LPS; Medzhitov and Janeway, 1997). These receptors are the key components for distinguishing between the host and the invader and defined as pathogen recognition receptors called toll-like receptors (TLR; Anderson, 2000), which mediate the elimination of the pathogenic microbes through phagocytosis and killing (Wingrove et al., 1992). TLRs regulate apoptosis, inflammation, and immune responses (Anderson, 2000). Evidence supporting a role for TLRmediated recognition of macrophage function in resolution of inflammation is accumulating providing strong support indicating that this receptor-ligand interaction is key to the homeostatic restoration of the host defense (Duffield et al., 2006; Schif-Zuck et al., 2011). Recently, a group of nucleotide-binding oligomerization domain proteins (NODs) have been described as potential regulators of apoptotic events and nuclear factor $\kappa B(\mathrm{NF}-\kappa \mathrm{b})$ activation within the context of pathogen recognition and the inflammatory responses (Inohara and Nunez, 2003). While it is not clear how NODs are involved in oral inflammatory diseases, evidence suggests that they are expressed in gingival cells and may play role in promotion of oral inflammation (Uehara and Takada, 2007; Tang et al., 2011).

The TLR family is the best-characterized class of pathogen recognition receptors. TLRs are unique receptors that recognize molecules, broadly shared by microorganisms, but are distinguishable from the host molecules, referred to as "pathogenassociated molecular patterns (PAMP).” TLRs detect multiple PAMPs, including LPS, bacterial lipoproteins and lipoteichoic acids, flagellin, CpG DNA of bacteria and viruses, double-stranded RNA, and single-stranded viral RNA (Iwasaki and Medzhitov, 2004). To date, 11 different TLRs have been identified (Liu et al., 2000; Takeda et al., 2003; Krutzik and Modlin, 2004; Quesniaux et al., 2004). When TLRs bind to antigens, series of intracellular events are initiated and the process leads to the production of cytokines, chemokines, and antimicrobial peptides (Donati et al., 2009). The binding can be through four different adapters. Each adapter has the potential of producing various cytokines stimulating NF- $\mathrm{B}$ pathway in the nucleus of the cell. Known adapter proteins of TLRs are MyD88, toll-interleukin-1 receptor domain 
containing adapter protein (TIRAP), toll-interleukin-1 receptor domain containing adapter-inducing interferon- $\beta$ (TRIF) and TRIF-related adapter molecule (TRAM). TLRs also utilize interleukin-1 receptor-associated kinase (IRAK), and TNF receptor-activated factor 6 (TRAF6; Jiang et al., 2000). Different TLRs induce different responses; for example, in dendritic cells, the interaction of TLR 4 and LPS results in the production of proinflammatory cytokines such as interleukin-12. TLR-2 and TLR 4 have been shown to be expressed in oral tissue cells. The same TLR can trigger different responses through different intracellular adapter proteins (Alexopoulou et al., 2001; Kaisho and Akira, 2002; Cook et al., 2004; Krutzik and Modlin, 2004; Watters et al., 2007). TLRs 1, 2, 4, 5, and 6 specialize in the recognition of mainly bacterial products that are unique to bacteria and not made by the host. This gives them the specificity to differ the invader from the host (Iwasaki and Medzhitov, 2004). Recognition by the TLR pathway is a crucial phase in inflammation. After recognition, many cytokines are released from various cell types including the macrophages through the NFкB pathway (Uehara and Takada, 2007). After TLR4 activation, MyD88 is recruited to TLR4 through respective Toll/IL-1 receptor (TIR)-TIR interactions (Medzhitov et al., 1998; Muzio et al., 1998; Raschi et al., 2003). MyD88 also contains a death domain (DD), a highly conserved protein-binding domain that facilitates its interaction with another DD-containing signaling molecule, IRAK (Cao et al., 1996). IRAK subsequently undergoes phosphorylation and dissociates from MyD88, interacts with TRAF6, and thereby activates several downstream kinases (Cao et al., 1996; Yamin and Miller, 1997; Aderem and Ulevitch, 2000; Jiang et al., 2000; Swantek et al., 2000; Raschi et al., 2003). Following LPS stimulation, two signaling pathways have been described, the MyD88-dependent and -independent pathways (Akira et al., 2000; Kawai et al., 2001; Sato et al., 2002; Yamamoto et al., 2003). Endotoxin activation of the MyD88-dependent pathway results in rapid NF- $\kappa \mathrm{B}$ activation and release of pro-inflammatory cytokines such as tumor necrosis factor-alpha (TNF- $\alpha)$ and IL-1 $\beta$. Endotoxin activation of the MyD88-independent pathway results in rapid activation of interferon regulatory factor 3 (IRF3) leading to beta interferon (IFN- $\beta$ ) release with delayed NF- $\kappa \mathrm{B}$ activation (Akira et al., 2000; Kawai et al., 2001; Hoebe et al., 2003). The TLR proteins possess leucine-rich extracellular repeats that recognize the LPS binding protein (LBP)-CD14 complex (Poltorak et al., 2000). The TLR intracellular domain resembles the IL-1 $\beta$ receptor, hence the term TIR homology domain (Medzhitov et al., 1997; Chaudhary et al., 1998; Rock et al., 1998). The TIR domain in the cytoplasmic portion of the molecule is considered essential for triggering activation of mitogen-activated protein kinases (MAPKs) and the transcription factor NF-кB (Means et al., 2000; Akira et al., 2001; Sato et al., 2002). While CD14 is the major LBP on the surface of mononuclear phagocytes, CD14 is not capable of transducing signals across the membrane. A receptor complex comprised of CD14, TLR-2, TLR4, and accessory proteins (MD2 ) is necessary for receptor function as well as various kinases, including the three classes of MAPK: extracellular signal-regulated kinase (ERK) 1 and ERK2 (Weinstein et al., 1992), p38 MAPK (Han et al., 1994), and c-Jun N-terminal kinases (JNK; Hambleton et al., 1996). Numerous inflammatory cytokines and mediators are expressed in LPS stimulated macrophages through activation of transcription factors including NF- $\mathrm{BB}$ and activator protein1 (Fujihara et al., 1993; Muroi et al., 1993; Guha and Mackman, 2001). LPS recognition is initiated by LBP, a serum glycoprotein, that first binds to the lipid A moiety of LPS (Schumann et al., 1990; Wright et al., 1990; Gegner et al., 1995). The LPS-LBP complex is then recognized by CD14 (Schumann et al., 1990; Ulevitch and Tobias, 1995; Haziot et al., 1996). Mice with a targeted deletion of the gene encoding CD14 are hyporesponsive to LPS and resistant to the lethal effects of LPS (Haziot et al., 1996). However, mice lacking CD14 are still able to respond to high concentrations of LPS (Wurfel et al., 1997). CD14 is a glycosylphosphatidylinositolanchored (GPI-anchored) molecule which lacks a cytoplasmic signaling domain, making it incapable of downstream signaling (Haziot et al., 1988). It is not fully clear if the TLR-mediated pathways are directly involved during the oral inflammatory responses including resolution.

We have previously identified moesin as a participant in LPS binding and signal transduction (Tohme et al., 1999). Many physiological and pathophysiological conditions are attributable in part to cytoskeletal regulation of cellular responses to signals. Moesin is an ERM (ezrin, radixin, and moesin) family member and was identified as part of a protein cluster. Moesin was found to be necessary for the detection of LPS, and homozygous moesin knockout mice exhibited a threefold reduction in neutrophil infiltration into LPS injected sites when compared to wild type controls (Amar et al., 2001). Anti-moesin antibody inhibited the release of TNF- $\alpha$ by LPS stimulated monocytes (Tohme et al., 1999), and moesin was also found to be expressed on the surface of differentiated THP-1 cells and primary peripheral blood monocytes. LPS stimulation increased the surface expression of moesin as well as its total protein levels when analyzed by FACS and Western blotting, respectively. Furthermore, moesin was found to co-immunoprecipitate with TLR4 after LPS stimulation (Iontcheva et al., 2004). In moesin mRNA knockdown experiments using antisense mRNA, THP-1 cells no longer responded to LPS (Iontcheva et al., 2004), suggesting a role for moesin in LPS signaling. Using differentiated THP-1 cells, co-immunoprecipitation experiments revealed that moesin and CD14 were associated in the cell membrane in both resting and LPS stimulated cells. TLR4 and MD-2 became associated with moesin and CD14 only after LPS stimulation. These experiments also demonstrated that there was a direct binding between moesin and LPS. Moesin was phosphorylated and mRNA levels of moesin increased significantly after LPS stimulation. During the TLR4mediated response to LPS, moesin stimulates the NF- $\kappa$ B, p38, and p44/42 MAPK activation (Iontcheva et al., 2004; Zawawi et al., 2010). Figure 1 shows a model for recognition of LPS involving the dynamic association of multiple molecules, including moesin, forming a cluster that functions as the LPS receptor and an important role in the macrophage-mediated innate immune response and TLR4-mediated pattern recognition in oral inflammatory diseases.

Cytokines and other products of macrophages can also modulate the action, differentiation, and survival of cells outside the immune system, such as the nervous system. The interaction between macrophages and the nervous system relies on the receptor-sensitizing characteristics of cytokines (Opree and Kress, 2000) linked to the discovery of protease-activated receptors 


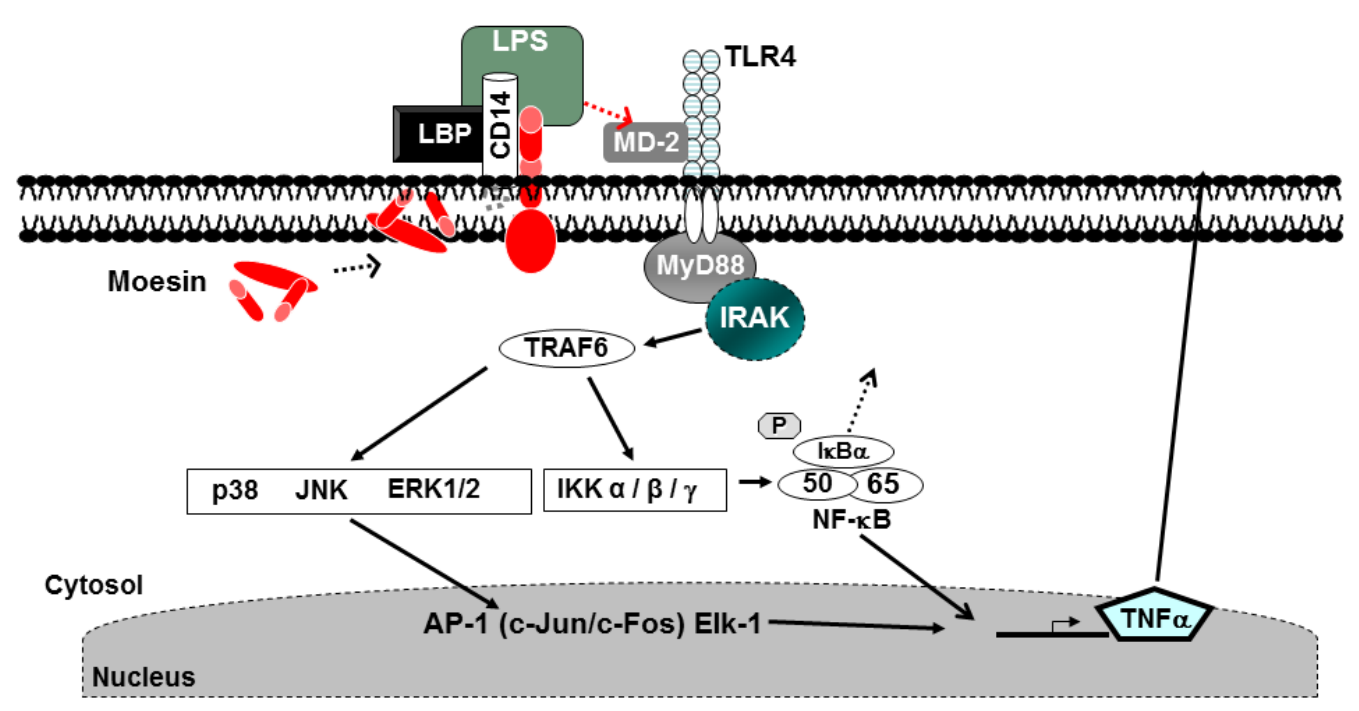

FIGURE 1 | Lipopolysaccharides (LPS) recognition and signaling in macrophages. CD14 and moesin are expressed on the cell membrane in macrophages. LPS stimulation results in phosphorylation of moesin, binding to the TLR4 and MD-2 activating the MyD88. Signaling through this mechanism leads to the production of pro-inflammatory cytokines (Zawawi et al., 2010).
(PARs). Research into the functionality of these receptors has shown that PAR-2 has a particularly important role in disease states associated with chronic inflammation (Vergnolle, 1999). Identification of neuropeptide receptors on immune cells indicates a communication between the immune and neurological systems that possibly results in the modulation of inflammatory response through G-protein-coupled receptors located on the cell membranes or the vanilloid receptor-1 (also named TRPV1), which is shown to be up-regulated in inflammatory bowel disease. These findings suggest a possible role for this receptor in chronic inflammation (McGillis et al., 1991; Yiangou et al., 2001; Tracey, 2002; Lundy and Linden, 2004). Cytokines have been shown to regulate substance P expression and response to LPS (Kessler and Freidin, 1993; Hua et al., 1996). Substance P limits the production of TGF$\beta$ by macrophages and induces synthesis of IL-6 (Lieb et al., 1996; Marriott and Bost, 1998). Macrophages can produce substance $\mathrm{P}$ when activated with LPS in vitro (Lambrecht et al., 1999). The precise mechanism through which these receptor-mediated events might regulate the macrophage response in the oral cavity is not clear; future research is needed to understand their role.

\section{ROLE OF MACROPHAGES IN GINGIVAL INFLAMMATION AND BONE RESORPTION}

Macrophages efficiently ingest particulate antigen, express MHC class II molecules and have co-stimulatory activity on $\mathrm{T}$ cells. Macrophages can be phenotypically polarized by the microenvironment. The classically activated macrophages (M1) are activated by IFN- $\gamma$ and LPS, and alternatively activated macrophages (M2) produced in response to IL-4 or IL-13 (Martinez et al., 2009). M2 macrophages have been shown to play role in resolution of inflammation with a reduced capacity to produce cytokines (Bhatavadekar and Williams, 2009). Cytokine and chemokine production by macrophages is a key step in immune response and the inflammation process. Cytokines interact between each other, amplify signaling, modulate cell surface receptors, and perform synergistic or antagonistic interactions on cell function (Balkwill and Burke, 1989). It is not only the presence of one cytokine that regulates the response, but the concentration of the same mediator can also affect the outcome of a response (Gemmell et al., 1997). Their secretion is dependent on the NF-кB in the nucleus of many immune system cells (Baldwin, 1996; Hanada and Yoshimura, 2002). In addition to macrophages, cytokines can be produced by both resident cells such as epithelial cells, fibroblasts and other phagocytes such as neutrophils in the periodontal tissues (Ara et al., 2009). After microbial recognition, cytokines in innate response such as TNF- $\alpha$, IL-1, and IL-6 are the first to start communication in disease pathogenesis (Garlet, 2010). IL-1 $\beta$ and IL- 6 are the signature innate cytokines and have been characteristically associated with inflammatory cell migration, highly produced by the macrophages and involved in osteoclastogenesis processes (Graves et al., 2008; Fonseca et al., 2009). TNF- $\alpha$ is a multi-role cytokine, that has many functions from cell migration to tissue destruction. It induces the up-regulation of adhesion molecules, stimulates the production of chemokines, and is involved in cell migration to infected and inflamed sites (Peschon et al., 1998; Dinarello, 2000; Wajant et al., 2003; Kindle et al., 2006). TNF- $\alpha$ up-regulates the production of other signature pro-inflammatory innate immunity cytokines, such as IL-1 $\beta$ and IL-6 (Okada et al., 1997; Dinarello, 2000; Wajant et al., 2003; Kwan Tat et al., 2004; Garlet et al., 2007; Graves et al., 2008; Musacchio et al., 2009). TNF$\alpha$ is also correlated with extracellular matrix (ECM) degradation and bone resorption through its positive correlation with matrix metalloproteinases (MMPs) and RANKL expression (Graves and Cochran, 2003; Garlet et al., 2004; Graves et al., 2008). Experimental periodontitis in TNF- $\alpha$ p55 receptor deficient mice was characterized by a significant decrease in MMPs and RANKL expression (Garlet et al., 2007). Thus, in addition to direct actions in bone resorption, macrophage-derived cytokines also interfere 
with the coupled bone formation process (Behl et al., 2008). IL13 is another potent modulator of human monocyte/macrophage function. Monocyte/macrophage cell surface markers, MHC class II and several integrin molecules are up-regulated by IL- 13 (de Waal Malefyt et al., 1993). The monocyte/macrophage related production of the cytokines IL- $1 \alpha$, IL- $1 \beta, 1 \mathrm{~L}-6$, IL- 8 , and TNF- $\alpha$ is also inhibited by IL- 13 . On the other hand, IL-1 receptor antagonist secretion is enhanced (de Waal Malefyt et al., 1993; Zurawski and de Vries, 1994). Therefore, IL-13, along with IL-4 and IL-10, would appear to have potential anti-inflammatory activity (Zurawski and de Vries, 1994).

In addition to their cell trafficking role, chemokines provide messages leading to other biological processes, such as angiogenesis, cell proliferation, apoptosis, tumor metastasis, and host defense (Rossi and Zlotnik, 2000; Zlotnik and Yoshie, 2000; Moser et al., 2004; Rot and von Andrian, 2004; Esche et al., 2005). Chemokines are classified into four subfamilies according to the configuration of cysteine residues near the $\mathrm{N}$-terminus. Chemokines engage their receptors. This binding initiates integrin-dependent adhesion, as well as the binding and detachment of cells from their substrate. Chemokines target all types of leukocytes of the innate immune system, as well as lymphocytes of the adaptive immune system (Terricabras et al., 2004). IL-8/CXCL8 is the first cytokine identified to have chemotactic activity. It can be produced by macrophages as well as fibroblasts, epithelial cells, and endothelial cells (Takashiba et al., 1992; Takigawa et al., 1994; Yumoto et al., 1999). IL-8 is a neutrophil chemoattractant. It is detectable in healthy and diseased periodontal tissues and has been associated with subclinical inflammation (Yoshimura et al., 1987; Payne et al., 1993; Mathur et al., 1996). It has direct action on osteoclast differentiation and activity by signaling through the specific receptor, CXCR1 (Bendre et al., 2003). Another crucial chemokine for macrophage function is MCP-1/CCL2, which mediates the recruitment of monocytes/macrophages (Hanazawa et al., 1993; Okamatsu et al., 2004). Together with RANTES/CCL5, MIP-1 $\alpha / C C L 3$ may also be involved in the migration of macrophages to oral tissues (Gemmell et al., 2001; Kabashima et al., 2002). CXCR3 and its ligand IP-10/CXCL10 are also expressed in diseased periodontal tissues and associated with higher levels of IFN- $\gamma$ during the inflammation process (Kabashima et al., 2002; Garlet et al., 2003). CCR4 is found expressed at higher levels in chronic periodontitis and it is associated with higher levels of IL-4 and IL-10 messages in the periodontium (Garlet et al., 2003, 2004).

In addition to recruitment of cells, chemokines are crucial in guiding adaptive immunity cells with a role in bone metabolism. MDC/CCL22, TARC/CCL17, and I- 309/CCL1 have been shown to attract Th2 and Treg cells via binding their CXCR 4 and CXCR 8 receptors (D'Ambrosio et al., 1998; Sallusto et al., 1998; Gu et al., 2000). Chemokines have been recognized as essential signals for the trafficking of osteoblast and osteoclast precursors, and consequently as potential modulators of bone homeostasis (Bendre et al., 2003; Wright et al., 2005). Chemokines are capable of regulating bone metabolism via CCR1, CCR2, CXCR3, and CXCR4 receptors expressed on osteoclast precursors, mature osteoclasts, and osteoblasts. These receptors have the ability to bind many different chemokines such as SDF-1/CXCL12,

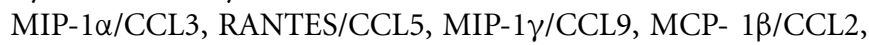

MCP-3/CCL7, MIG/CXCL9, and CK $\beta 8 / C C L 23$ (Votta et al., 2000; Lean et al., 2002; Okamatsu et al., 2004; Yu et al., 2004; Kwak et al., 2005; Wright et al., 2005; Kim et al., 2006a,b; Yang et al., 2006). IP-10/CXCL10 induces osteoblast proliferation through receptor CCR3 (Grassi et al., 2003; Lisignoli et al., 2004), while SDF$1 \alpha /$ CXCL12 and BCA-1/CXCL13 induce both proliferation and collagen type I mRNA expression in osteoblasts through receptors CCR4 and CCR5 (Lisignoli et al., 2006). In addition to its role in osteoclastogenesis, chemokines also affect osteoclast functions. It has been reported that SDF- $1 \alpha / C X C L 12$ increases MMP- 9 activity in human osteoclasts, resulting in increased bone resorption activity (Grassi et al., 2004). There is evidence that RANTES/CCL5 can also act on osteoblasts, resulting in chemotaxis and promoting cell survival (Yano et al., 2005). RANKL also induces the production of MCP-1/CCL2, MIP-1_/CCL3, RANTES/CCL5, and MIG/CXCL9 by osteoclasts, suggesting a coupling role, which could contribute to bone resorption (Kim et al., 2006a). Taken together, these studies suggest that macrophage-produced chemokines can effectively contribute to the bone remodeling process by driving osteoblast migration and activation during periodontal wound healing.

An important key mediator of macrophage function is the prostaglandins, which are derived from hydrolysis of membrane phospholipids. Phospholipase $\mathrm{A}_{2}$, cleaves arachidonic acid, a precursor of a group of small lipids known as eicosanoids, from membrane phospholipids. Eicosanoids generally act as inflammatory agents (Lewis, 1990). Arachidonic acid is metabolized via two enzymatic pathways. The first is the action of lipoxygenases that results in the formation of the hydroxyeicosatetraenoic acids (HETE) and leukotrienes (LT). Alternatively, cyclooxygenases (COX) catalyze the conversion of arachidonic acid into prostaglandins, prostacyclins, and thromboxanes. Prostaglandins have 10 sub-classes, of which D, E, F G, H, and I are the most important (Gemmell et al., 1997). Inflamed oral tissues synthesize significantly large amounts of prostaglandins (Mendieta et al., 1985). Prostaglandin $E_{2}$ is the most potent stimulator of alveolar bone resorption (Goodson et al., 1974; Dietrich et al., 1975). Within oral lesions, prostaglandin $\mathrm{E}_{2}$ is mainly localized within macrophage-like cells and secreted when stimulated with bacteria LPS (Loning et al., 1980). Periodontal ligament cells also produce prostaglandin $\mathrm{E}_{2}$ even at rest. This secretion is enhanced by IL$1 \beta$, TNF- $\alpha$, and parathyroid hormone (Richards and Rutherford, 1988; Saito et al., 1990a,b). Prostaglandin $E_{2}$ has a biphasic action on cells; in high doses, it decreases IgG levels but in low doses has the potential to increase them. When combined with IL-4, low doses of prostaglandin $\mathrm{E}_{2}$ induce a synergistic rise in IgG production, suggesting an immune-regulatory role for prostaglandin $\mathrm{E}_{2}$ (Harrell and Stein, 1995).

Disruption of the balance between osteoblast and osteoclast activities by bacterial products and inflammatory cytokines constitutes the main underlying causes of inflammation-induced bone loss (Liu et al., 2000). It is shown that LPS of bacteria either directly or through its action on the macrophages is capable of stimulating bone resorption when added to osteoclast precursor cultures containing osteoblasts and/or stromal cells (Iino and Hopps, 1984). In addition to this, TLR and inflammation-induced osteoclastogenesis pathway is the most common pathway related to bone loss (The American Academy of Periodontology Academy 
Report, 1999; Pihlstrom et al., 2005). Inflammation-induced and macrophage-mediated bone loss in oral infection involves complex inflammatory signals and cytokine networks regulating osteoclastogenesis, such as RANKL, interleukin-1, interleukin-6, tumor necrosis factor- $\alpha$, and prostaglandin $\mathrm{E}_{2}$ have been reported to be significantly associated with this type of tissue destruction (Henderson et al., 2003). Before the discovery of receptor activator of $\mathrm{NK \kappa \textrm {B }}$ (RANK), its ligand (RANKL), and its antagonist osteoprotegerin (OPG), the development and formation of osteoclasts were attributed to factors produced by osteoblasts and bone marrow stromal cells (Rodan and Martin, 1981; Martin and Sims, 2005). It is now clear that RANKL, RANK, OPG are the key regulators of bone remodeling, directly involved in the differentiation, activation, and survival of osteoclasts and osteoclast precursors (Anderson et al., 1997; Lacey et al., 1998; Yasuda et al., 1998). RANKL is expressed by osteoblasts, stromal cells, chondrocytes, and other mesenchymal cells. Activated T and B cells can also express RANKL (Theill et al., 2002; Mahamed et al., 2005; Kawai et al., 2006). RANK is expressed by osteoclast progenitors, mature osteoclasts, chondrocytes, monocytes/macrophages, and dendritic cells (Anderson et al., 1997; Hsu et al., 1999). Their decoy receptor OPG is known to be expressed by periodontal tissue cells like fibroblasts and periodontal ligament cells (Liu et al., 2000). Blocking RANKL activity with OPG significantly inhibits bone loss in rheumatoid arthritis, osteoporosis, cancer-related bone metastasis, and diabetes associated alveolar bone destruction (Mizuno et al., 1998; Kong et al., 1999; Honore et al., 2000; Brown et al., 2004; Hofbauer and Schoppet, 2004; Mahamed et al., 2005), confirming the critical role of the RANKL, RANK, OPG triad in osteoclastogenesis. Osteoclastogenesis via RANK, RANKL pathway depends on Macrophage-Colony Stimulating Factor (M-CSF; Tanaka et al., 1993; MacDonald et al., 2005). Pathogens, stress, or pathology influence the production of M-CSF via pro-inflammatory cytokines and have a significant role on the subsequent osteoclast activity where TLR-2 activation upregulates the expression of M-CSF (Song et al., 2009). LPS from different pathogens can stimulate bone resorption in vitro and in animal models as in primary mouse calvarial osteoblasts, the activation of TLR-2 and TLR- 6 by LPS causes enhanced expression of RANKL through a MyD88-dependent mechanism (Sato et al., 2004). In mouse calvarial osteoblasts, expression of TLR 4 and TLR-9 results in the activation of $N F \kappa B$ and related to that the increased secretion of TNF- $\alpha$ and M-CSF (Morse et al., 2008). LPS-induced interleukin-1 production through TLR pathway can up-regulate RANKL and inhibit osteoprotegerin expression by osteoblasts resulting in osteoclast formation in a prostaglandin E2dependent manner. TLR-2 substantially decreases the responses to LPS (Song et al., 2009). LPS directly, or via TLR pathway by stimulating different cell types is capable of inducing osteoclast development and activity. Thus, TLRs could influence the inflammatory response in the bone microenvironment, and may play a critical role in modulating inflammation-induced osteoclastogenesis and bone loss.

Another mechanism underlying macrophage involvement in oral tissue pathologies is the destruction of ECM. Collagenases, along with other MMPs, play an important role in this process. MMPs are a family of structurally related but genetically distinct enzymes that degrade ECM and basement membrane components. Twenty-three enzymes have been classified into collagenases, gelatinases, stromelysins, membrane-type MMPs, and other MMPs, mainly based on the substrate specificity and molecular structure. MMPs are involved in physiological processes such as tissue development, remodeling, and wound healing. MMP activity is controlled by changes in the delicate balance between the expression and synthesis of MMPs and their major endogenous inhibitors, tissue inhibitors of MMPs (TIMPs). It is clear that MMPs are up-regulated in periodontal as well as other types of oral inflammation (Ebert et al., 2005). MMP activation involves tissue and plasma proteinases and bacterial proteinases together with oxidative stress (Henry et al., 2002; Rot and von Andrian, 2004). It is now clear that a broad range of cell types present in the normal and diseased human periodontium such as gingival sulcular epithelial cells, fibroblasts and endothelial cells, monocytes/macrophages, neutrophils, and plasma cells has the ability to express distinct MMPs (Sorsa et al., 1995; Takagi et al., 1995; Kiili et al., 2002; Wahlgren et al., 2002).

Matrix metalloproteinases gene transcription is very low in the healthy periodontal tissue; their secretion is stimulated or downregulated by various cytokines. The main stimulatory cytokines for MMPs are TNF- $\alpha$, IL-1, and IL-6. Activated MMPs are capable of activating other MMPs (Visse and Nagase, 2003). There is a close interaction between MMP activation and cytokine function. IL-1 $\beta$ and TNF- $\alpha$ can stimulate MMP-3, MMP-8, and MMP-9 secretions from gingival fibroblasts and MMP- 13 in osteoblasts. TGF- $\beta$ a suppresses MMP-1, MMP-3, and MMP-8 gene transcription but induces MMP-2 and MMP-13 in keratinocytes (Birkedal-Hansen, 1993; Kahari and Saarialho-Kere, 1999; Konttinen et al., 1999). MMP-1 (collagenase-1) has a wide range of substrates. It can digest interstitial collagen, ECM components, and soluble nonmatrix mediators (Sorsa et al., 2006). MMP-9 (gelatinase B) is a gelatinolytic enzyme degrading several ECM proteins, including basement membrane-type IV collagen (Lee et al., 1995; Sume et al., 2010; Kantarci et al., 2011). MMP-9 is found to be expressed in epithelial cells; its production can be stimulated by several cytokines such as TNF- $\alpha$, growth factors such as epidermal growth factor, and by some bacterial products such as LPS (Putnins et al., 1996; Firth et al., 1997). Although MMP-1, MMP-8, and MMP9 are the main enzymes that are involved in the ECM and base membrane breakdown, other MMPs and their tissue inhibitors (TIMPs) have also been linked to periodontal diseases. MMP-2 (gelatinase A) has been shown to be strongly expressed in inflamed pocket epithelium and to be important in epithelial cell migration (Makela et al., 1999). MMP-13 (collagenase-3) is expressed by the basal cells of the gingival pocket epithelium able to degrade collagens type I, III, and IV as well as fibronectin, tenascin, and some proteoglycans (Kahari and Saarialho-Kere, 1997; Knauper et al., 1997; Uitto et al., 1998). MMP-13 plays an important role in the ability of pocket epithelium to invade periodontal connective tissue. Some oral bacterial species, especially Fusobacterium nucleatum were found to induce MMP-13 (Uitto et al., 2003).

\section{RESOLUTION OF ORAL INFLAMMATION AND THE ROLE OF MACROPHAGES}

Oral inflammatory diseases can be considered as an adverse outcome of the protection efforts of the host against the invading 
pathogens. Inflammation should resolve in a timely manner to prevent tissue injury, and maintain health. The rapid and complete elimination of invading leukocytes from a lesion is the ideal outcome following an inflammatory event (Schwab et al., 2007). Inadequate resolution and failure to return tissue to homeostasis results in neutrophil-mediated destruction and chronic inflammation (Van Dyke and Serhan, 2003). If the host is unable to neutralize the pathogens, then acute inflammation would become chronic with consequences such as destruction of ECM and bone, scarring, and fibrosis (Van Dyke, 2008). Controlling the invasion of the neutrophils can impact the conversion of an acute gingivitis to chronic periodontitis. Scarring and fibrosis in periodontitis prevents the return to homeostasis (Van Dyke, 2007). When tissue injury is mild, necrotic cells will be replaced by new cells by regeneration process. If tissue damage is extensive, the process of healing is repair. When repair takes place, fibrin is not cleared rapidly and efficiently after the acute phase of inflammation and granulation tissue is formed from surrounding tissue compartments. Later phases of repair involve fibroblastmediated collagen deposition, disappearance of vascular tissues and replacement of these areas by avascular and fibrotic scar tissue (Kumar et al., 2005). The efforts to control inflammation process has been mainly with the use of pharmacologic agents, which act as antagonists for some of the mediators of inflammation (Serhan et al., 2007). The resolution of inflammation previously thought to be a passive event, but greater understanding of the pathways and processes underlying resolution of inflammation has led to the recognition of an active progress where the activation of pro-resolving molecules are needed to neutralize and eliminate inflammatory leukocytes, and thereby prevent pathology (Van Dyke and Serhan, 2003; Van Dyke, 2007; Serhan et al., 2008). Restoration of tissue homeostasis is initiated following an acute inflammatory response that generates lipid mediators of inflammation (Van Dyke, 2008). Various lipid mediators such as eicosanoids, prostanoids, and prostacyclins are produced upon agonist stimulation of G-protein receptors on the cell membrane. Arachidonic acid (AA) plays key role in this process (Kantarci and Van Dyke, 2003) and is metabolized either by a cyclooxygenase (COX)-1 or COX-2-dependent pathway that results in the generation of prostanoids or a 5-lipoxygenase (5-LO)-dependent pathway that results in leukotriene (LT) production.

There is a high concentration of cells containing lipoxygenases, and corresponding pro-inflammatory products, a "class switch" may occur within neutrophils (Levy et al., 2001; Van Dyke, 2007). This class switch gives rise to the synthesis of pro-resolving molecules. One of the active resolution molecules is lipoxins, which are generated late in inflammation when a second lipoxygenase interacts with a lipoxygenase product generated earlier by a different cell (Serhan, 2004). These molecules are synthesized through a series of enzymatic reactions starting with the oxidation of AA by 15 LO through the process of transcellular biosynthesis, resulting in 15-S-hyroxy- $(p)$-eicosatetraenoic acid [15- $S$-H $(p)$ ETE]. Accordingly, $15-S-\mathrm{H}(p)$ ETE is further acted on by $5-\mathrm{LO}$ to induce the synthesis of lipoxins, such as lipoxins $\mathrm{A}_{4}\left(\mathrm{LXA}_{4}\right)$ and $\mathrm{B}_{4}\left(\mathrm{LXB}_{4}\right.$; Kantarci and Van Dyke, 2003; Van Dyke and Serhan, 2003). The lipoxins produced act as agonists to stimulate the resolution of inflammation and promote the restoration of tissue homeostasis through a number of mechanisms. These include limiting PMN migration into sites of inflammation, activating monocytes without the generation of a superoxide anion, and stimulating the uptake of apoptotic PMN by macrophages (Serhan et al., 1993; Maddox and Serhan, 1996; Maddox et al., 1997). When the lipoxin pathway is activated and aspirin is present during this synthesis, acetylation of the COX-2 enzyme occurs to inhibit further production of prostanoids from AA metabolism. This alternative pathway will lead to the synthesis of $15-\mathrm{R}-\mathrm{H}(p)$ ETE transforming to 5(6)epoxytetraene with the help of 5-LO activity. The next step is the synthesis of 15-epi-LXs or aspirin-triggered lipoxins (ATLs) from 5(6)-epoxytetraene (Van Dyke and Serhan, 2003). 15-epi-LX is a form of native lipoxin and possesses potent pro-resolving properties (Serhan et al., 1995; Claria et al., 1996; Van Dyke and Serhan, 2003).

In addition to the omega- 6 derived pro-resolving molecules, resolvins, and protectins are derived from the omega-3 polyunsaturated fatty acids (PUFAs), eicosapentaenoic acid (EPA), and docosahexaenoic acid (DHA; Van Dyke, 2007; Serhan and Chiang, 2008). They are able to stimulate anti-inflammatory and proresolving pathways similar to the lipoxins, but their binding sites on inflammatory cells differ from each other (Serhan et al., 2004; Van Dyke, 2007; Serhan and Chiang, 2008). Resolvins stimulate the resolution of inflammation through multiple mechanisms, including preventing neutrophil penetration, phagocytosing apoptotic neutrophils to clear the lesion, and enhancing clearance of inflammation within the lesion to promote tissue regeneration (Bannenberg et al., 2005; Hasturk et al., 2007; Schwab et al., 2007). The classic inflammatory eicosanoids (i.e., prostaglandins and leukotrienes), in addition to activating and amplifying the cardinal signs of inflammation, are also responsible for inducing the production of mediators that have both anti-inflammatory and pro-resolution activities, such as the lipoxins, resolvins, and protectins, reinforcing the active nature of the resolution process (Serhan et al., 2008). In humans, the aspirin-tolerant subjects generated both $\mathrm{LXA}_{4}$ and ATL, but aspirin-intolerant patients proved to have a diminished capacity to generate ATL and LX upon aspirin challenge (Sanak et al., 2000). In an experimental periodontitis rabbit model, animals are protected by $\mathrm{LXA}_{4}$ and transgenic (TG) rabbits over expressing 15 LO generate enhanced levels of LX, exhibit a reduced inflammatory phenotype, and are protected from bone loss in periodontal disease (Serhan et al., 2003). The treatment with Resolvin-E1 (RvE1) prevented and completely eliminated the signs of inflammation. In the RvE1 treated group, inflammation was completely eliminated; pocket depth was returned to normal and soft tissues returned to healthy levels and appearance (Figure 2). Regeneration of new cementum and bone with an organized periodontal ligament was observed (Hasturk et al., 2007). Restoration of crestal bone height, elimination of infrabony defects, and regeneration of new cementum, connective tissue, and bone with an organized periodontal ligament were signs of complete regeneration of tissues to pre-disease levels (Hasturk et al., 2007). Periodontitis was also shown to have a systemic impact elevating the levels of IL-1 $\beta$ and C-reactive protein (CRP) in all animals. Oral topical RvE1 therapy reduced systemic IL-1 $\beta$ and CRP levels. Rabbits treated with RvE1 showed an essentially complete recovery without any signs of local and 


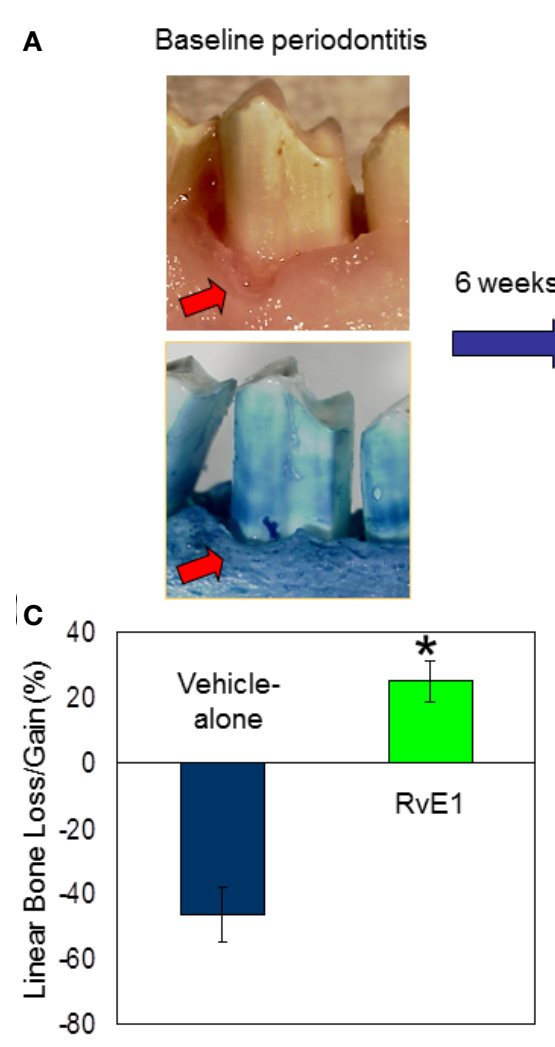

FIGURE 2 | Regulation of inflammation by resolvin-E1 in experimental periodontitis. (A) Periodontal disease was induced by ligature and Porphyromonas gingivalis application over 6 weeks in rabbits. Classical characteristic of periodontal disease including tissue and bone loss were observed. (B) Sites were treated either with RvE1 $(1 \mathrm{mg} / \mathrm{ml})$ or vehicle (ethanol) for an additional 6 weeks. RvE1 treatment did not only stop the disease progression but also reversed the tissue and bone loss and allowed the tissues to reach to a completely healthy
B

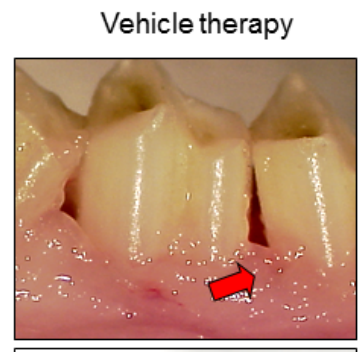

\section{RvE1 therapy}

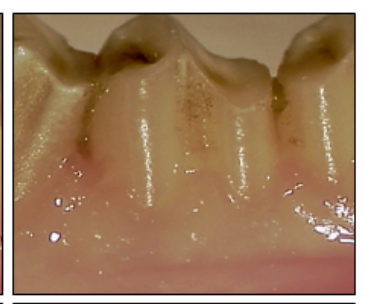

D
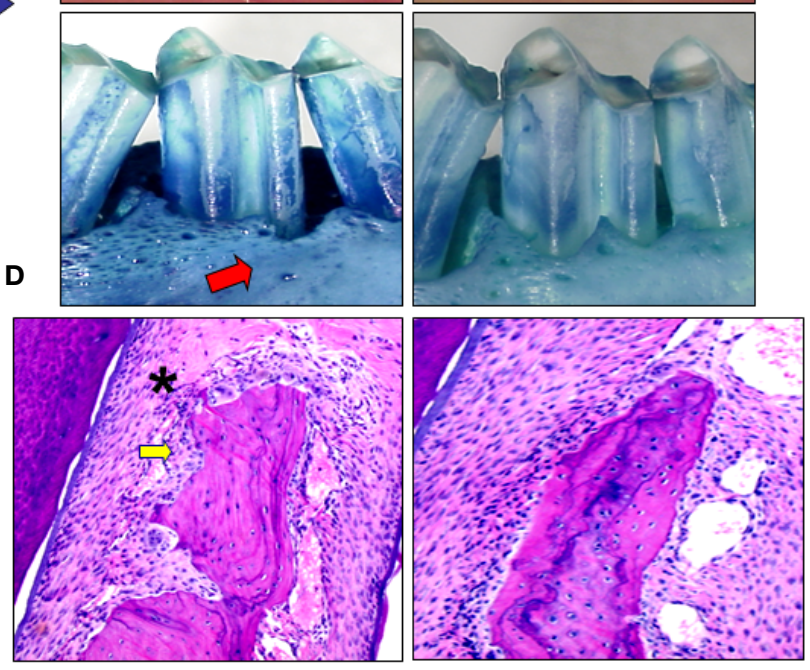

systemic inflammation (Hasturk et al., 2007) suggesting a complete return to tissue homeostasis. This mechanism is most likely regulated through an orchestrated series of events where in addition to neutrophils and lymphocytes, macrophages play the pivotal role.

\section{MACROPHAGES AS A POSSIBLE LINK BETWEEN ORAL AND SYSTEMIC INFLAMMATION}

The critical role of the macrophages in inflammatory diseases has been studied extensively in various organ systems in the human body. While the debate over the direction and cross-reactivity of local and systemic inflammation continues regarding which of the local specialized tissues are affected by systemic inflammatory changes and how the specific inflammatory processes in any part of the body have a generalized impact distant to the affected site, it is thought that the relationship is bidirectional (Offenbacher and Salvi, 1999; Amar et al., 2007; Ebersole et al., 2010; Hajishengallis, 2010). Such a dynamic response requires an intricate network of cellular and non-cellular components where macrophages are at the epicenter due to their extensive functional interactions with other cells and processes of inflammation. To this end, research has state. Vehicle treatment did not have any impact on controlling the disease, conversely the disease continued to progress. (C) Histological evaluations confirmed the clinical observations where RvE1 treated sites showed no bone loss and no or minimal inflammatory cell activity. (D) Histomorphometric evaluations quantified the bone level changes during these treatments over 6 weeks. While RvE1 treatment resulted in bone gain, vehicle treatment showed worsening and lost more bone as a result of disease progression. provided evidence of an oral and systemic connection in several diseases such as diabetes, cardiovascular diseases, and pathological conditions such as pre-term birth (Paquette et al., 1999; Nassar et al., 2007; Offenbacher et al., 2009).

We have previously studied macrophages and their role in the aggravation of inflammation in diabetics and identified critical markers of regulation at cellular signal transduction. These series of studies have demonstrated that oxidative stress plays a substantial role in the pathogenesis of diabetic complications. Superoxide anion is the first molecule generated during the respiratory burst of phagocytes, including macrophages, by NADPH oxidase. Either at rest or after stimulation with PMA or opsonized zymosan (OPZ), monocytes from people with diabetes produced significantly more anion than those from healthy individuals. The increased anion generation was found to be correlated with glycemic control (HbA1c) of patients. To clarify the impact of hyperglycemia on superoxide generation, normal human monocytes were then treated with receptor for advanced glycation end products (RAGE) ligands (advanced glycation end product, AGE protein and S100B) or high glucose media before stimulation. Both RAGE ligands and high glucose concentration increased 
A

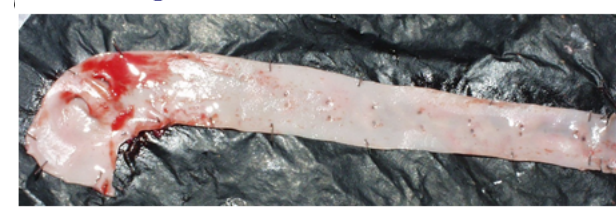

High Cholesterol Diet + Periodontitis

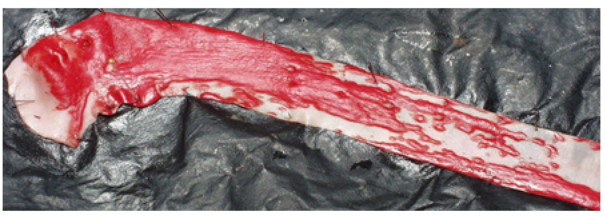

C

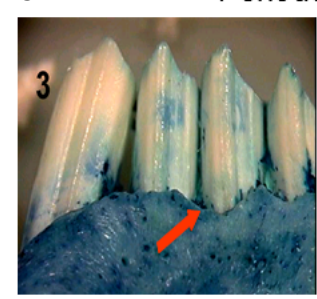

Normal Diet
Periodontitis

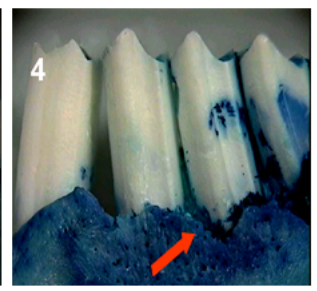

High Cholesterol Diet
B

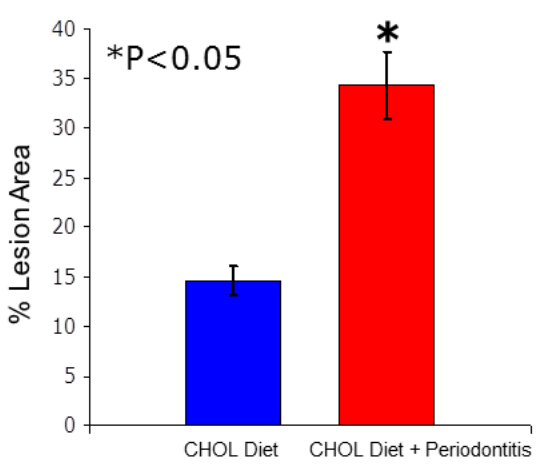

D

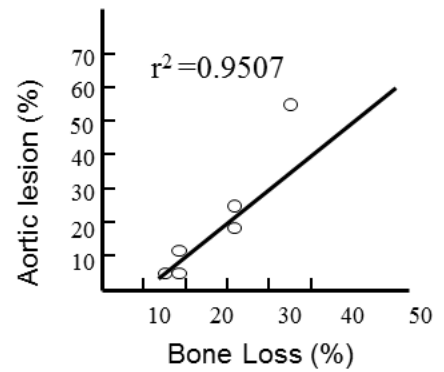

FIGURE 3 | Local periodontal inflammation as a modifier of atherosclerotic changes in aortas of high cholesterol-fed rabbits.

(A) Atherosclerosis was induced by high cholesterol diet $(0.5 \%)$ in rabbits over 13 weeks. Simultaneously, periodontal disease was also induced as explained above over a 6-weeks period. At 13 weeks, the aortas dissected en face and stained with Sudan IV for detection of lipid depositions. As a result of high cholesterol diet, rabbits developed early fatty streaks as indicated by Sudan IV stained lipid depositions mainly limited at the aortic arch and thoracic aorta. Rabbits challenged with $P$. gingivalis showed anion generation from human macrophages. Notably, high glucose was associated with correspondingly increased osmotic pressure. This study demonstrated that RAGE ligands can significantly contribute to the hyper-responsive phenotype of diabetic monocytes and macrophages, which might be reversible by blocking RAGE or reducing RAGE ligands by controlling hyperglycemia (Ding et al., 2007a).

Hyperglycemic episodes in diabetes are closely associated with increased oxidative and nitrosative stress, which can trigger the development of diabetic complications. Hyperglycemia stimulates the production of advanced glycosylated end products, activates protein kinase $\mathrm{C}$, and enhances the polyol pathway leading to increased superoxide anion formation. Superoxide anion interacts with nitric oxide, forming the potent cytotoxin peroxynitrite, which attacks various biomolecules in the vascular endothelium, vascular smooth muscle, and myocardium, leading to cardiovascular dysfunction (Pacher et al., 2005). High concentrations of hydrogen peroxide activate insulin signaling and induce typical metabolic actions of Czech et al. (1974). The pathogenetic role of nitrosative stress and peroxynitrite, and downstream mechanisms including poly(ADP-ribose) polymerase (PARP) activation. PARP activation can also up-regulate various pro-inflammatory pathways which leads to pathological dramatically more and extended level of lipid depositions covering almost entire surfaces of thoracic and abdominal aortas. (B) Quantification of lipid covered area clearly showed that local periodontal inflammation significantly increases the atherosclerotic changes induced by cholesterol diet. (C) Periodontal disease was also more dramatic in those rabbits received high cholesterol diet suggesting a reciprocal relationship between local and systemic inflammations. (D) The severity of bone loss was positively correlated with degree of the fatty streaks (lipid depositions; $r^{2}=0.9501$ ).

modifications in adhesion molecule expression, angiogenesis, and other processes (Virag and Szabo, 2002).

In order to identify the specific signaling pathway through which the RAGE-mediated functional changes are effected in macrophages in diabetic people, we focused on the enzyme systems, which regulate the oxidative burst in macrophages. To this end, our research has shown that an alteration in the protein kinase $\mathrm{C}$ (PKC) family of intracellular enzymes, which plays a crucial role in signaling for a variety of cellular responses of mononuclear phagocytes including phagocytosis, oxidative burst, and secretion, are directly involved in the pathogenesis of the complications of diabetes. The consequences of PKC activation were evaluated by endogenous phosphorylation of PKC substrates with a phosphospecific PKC substrate antibody $[\mathrm{pPKC}(\mathrm{s})]$. Phosphorylation of a 40-kDa protein was significantly increased in mononuclear phagocytes from diabetics as a downstream marker of PKC activation, and its phosphorylated form was found to be associated with the membrane. Through a wide range of techniques including the mass spectrometry, immunoprecipitation, and immunoblotting, we have identified this protein as pleckstrin. Phosphorylation and translocation of pleckstrin in response to the activation of RAGE suggested that pleckstrin was involved in RAGE signaling and AGE-elicited macrophage dysfunction. Suppression of 


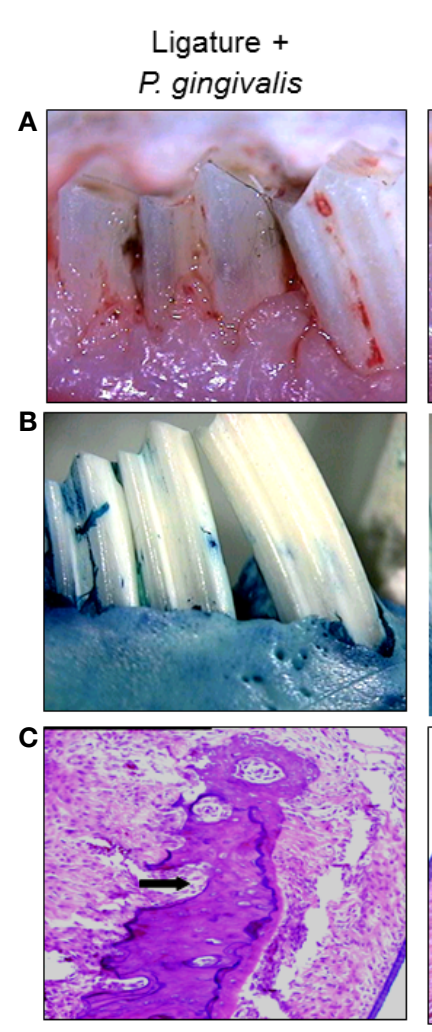

Ligature +

P. gingivalis

B
Ligature +

$P$. gingivalis $+\mathrm{LXA}_{4}$
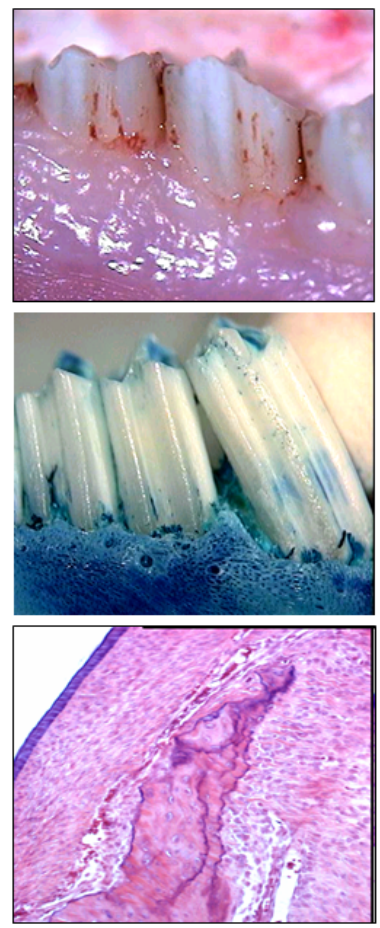

15-LO transgenic

Ligature $+P$. gingivalis
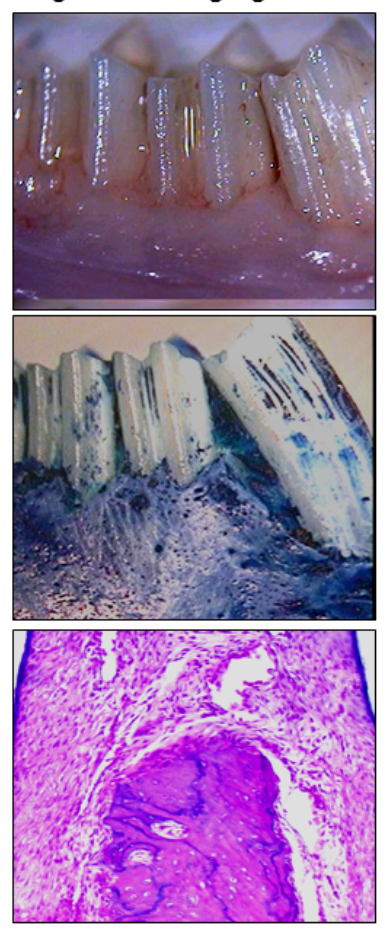

FIGURE 4 | Lipoxin $A_{4}$, a resolution phase agonist, conferred similar actions with RvE1 on periodontal tissues challenged by $\boldsymbol{P}$ gingivalis and ligature. (A) Periodontal inflammation was induced in transgenic and non-transgenic rabbits as described elsewhere for 6 weeks. Simultaneously, topical $\mathrm{LXA}_{4}(5-6 \mu \mathrm{g} / \mathrm{site})$ was applied to the ligated sites in some non-transgenic animals. At 6 weeks, similar to RvE1, Lipoxin $A_{4}$ resulted in significant reduction of tissue inflammation as a result of disease initiation. 15 LO overexpressing transgenic rabbits (15 LO-TG) exhibited no inflammation or tissue destruction and were completely protected from periodontal inflammatory changes. (B) The defleshed specimens clearly showed the amount of bone loss as a result of the periodontal disease induced by the human oral microorganism, $P$. gingivalis (left panel). $L X A_{4}$ was capable of preventing from these inflammatory changes and bone loss (middle panel), while the 15 LO-TG rabbits were not affected by disease induction, and were completely resistant to the disease (right panel). (C) Histological evaluations have confirmed the clinical observations and once again showed a complete protection in 15 LO-TG rabbits from inflammatory changes demonstrated by an unaffected healthy bony architecture (right panel). Topical LXA $\mathrm{A}_{4}$ application protected from the destructive effects of periodontal disease as indicated by histological evaluations (middle panel). pleckstrin expression with RNAi silencing revealed that phosphorylation of pleckstrin is an important intermediate in the secretion and activation pathways of pro-inflammatory cytokines (TNF- $\alpha$ and IL-1 $\beta$ ) induced by RAGE activation. Thus, phosphorylation of pleckstrin up-regulated in diabetic mononuclear phagocytes was in part due to the activation of PKC through RAGE binding, and pleckstrin was a critical molecule for pro-inflammatory cytokine secretion in response to elevated AGE in diabetes in macrophages (Ding et al., 2007b).

Cardiovascular diseases and oral inflammation is also linked through the pivotal role of the macrophages. Epidemiological and recent clinical studies have implicated periodontitis as a risk factor for cardiovascular disease. Leukocytes can affect the vascular endothelial lining and can cause oxidation of lowdensity lipoprotein (LDL). Monocytes are induced to become macrophages, which take up modified lipoproteins and become lipid-laden "foam cells" (Paigen et al., 1987a,b). The local inflammation is sustained by secreting chemical mediators. Activated macrophages in the atherogenic plaque produce inflammatory cytokines (interferon, interleukin-1, and TNF- $\alpha$ ), which induce the production of substantial amounts of interleukin-6. These cytokines are also produced in various tissues in response to infection and in the adipose tissue of patients with metabolic syndrome (Hansson, 2005). Interleukin-6, in turn, stimulates the production of large amounts of acute phase reactants, including CRP, serum amyloid A, and fibrinogen, by the liver (Ridker et al., 2000). CRP, the well-accepted marker of atherosclerotic disease, is shown to activate complement and accounts for LDL uptake by macrophages (Zwaka et al., 2001). The atherosclerotic lesion begins to bulge within the luminal wall and as the lesion progresses; the ECM is degraded by proteolytic enzymes and becomes susceptible to rupture. Thromboses can occur, occluding blood flow to the heart, which may eventually lead to infarction.

While macrophages play a central role in the development of atherosclerosis, specifically in the initial accumulation of cholesterol in the arterial wall (Ross, 1993), it has been suggested that infection and chronic inflammatory conditions such as periodontitis may influence the atherosclerosis process (Haraszthy et al., 2000). P. gingivalis, one of the major pathogens involved in periodontitis, has been detected in human atheromas (Deshpande 
et al., 1998; Dorn et al., 2000) suggesting that $P$. gingivalis infection may be associated with atherosclerosis. It has been proposed that bacteria or viruses may infect atherosclerotic lesions contributing to the inflammatory process. Distant infections may increase systemic inflammation through the release of toxins (i.e., bacterial LPS) or the leakage of chemical mediators into the circulation (Qi et al., 2003). Although multiple cross-sectional studies have supported these hypotheses by demonstrating a higher incidence of atherosclerotic complications in patients with periodontal disease (Mattila et al., 1989; Arbes et al., 1999) and suggest a strong link between periodontal inflammation and atherosclerosis (DeStefano et al., 1993), these observational studies are far from proving causation as proposed. Experimental animal models where periodontitis and atherosclerosis were developed in the same animal have been recently used to address this challenge. The ApoE-null mouse periodontal disease model was able to demonstrate that experimental induction of periodontal disease by serial inoculations of $P$. gingivalis exacerbated early atherosclerotic lesions (fatty streaks) within 4 months (Lalla et al., 2003). In addition, serum IL-6, aortic VCAM-1, and tissue factor antigen levels were increased in mice with $P$. gingivalis infection. In parallel, our group has shown that $P$. gingivalis induced periodontitis in rabbits dramatically increased lipid deposition in the aortas of cholesterolfed rabbits compared to high cholesterol diet alone within 13 weeks (Jain et al., 2003). Animals with experimentally induced periodontitis had more extensive accumulations of lipids in the aorta compared to non-periodontitis animals $(P<0.05)$, and there was a positive correlation between the severity of periodontal disease and the extent of lipid deposition $\left(r^{2}=0.9501\right.$; Figure 3$)$. In this study, $P$. gingivalis $16 \mathrm{~S}$ ribosomal RNA were not found in atheromatous plaques supporting the concept that rather than the bacteria itself, $P$. gingivalis cells or its vesicles released from periodontal lesions into the circulation may deliver virulence factor(s) such as LPS to the arterial wall to initiate or promote foam cell formation by macrophages and contribute to atheroma development (Qi et al., 2003). In a subsequent study, transgenic rabbits overexpressing 15-lipoxygenases and their response to inflammatory

\section{REFERENCES}

Aderem, A., and Ulevitch, R. J. (2000). Toll-like receptors in the induction of the innate immune response. Nature 406, 782-787.

Akira, S., Hoshino, K., and Kaisho, T. (2000). The role of Toll-like receptors and MyD88 in innate immune responses. J. Endotoxin Res. 6, 383-387.

Akira, S., Takeda, K., and Kaisho, T. (2001). Toll-like receptors: critical proteins linking innate and acquired immunity. Nat. Immunol. 2, 675-680.

Alexopoulou, L., Holt, A. C., Medzhitov, R., and Flavell, R. A. (2001). Recognition of double-stranded RNA and activation of NF-kappaB by Toll-like receptor 3. Nature 413, 732-738.

Amar, S., Oyaisu, K., Li, L., and Van Dyke, T. (2001). Moesin: a potential challenge were examined. Periodontal disease was initiated by topical $P$. gingivalis application. 15 LO-TG rabbits exhibited markedly reduced bone loss and local inflammation compared to nontransgenic rabbits where a significant amount of tissue destruction was observed (Figure 4). Further, application of topical aspirintriggered lipoxin $\left(\mathrm{LXA}_{4}\right)$ to the gingival site dampened the PMNmediated tissue breakdown and bone loss suggesting that regulation of inflammation can provide an enhanced anti-inflammation status, which results in prevention of periodontal inflammation (Serhan et al., 2003). Overexpression of 15-lipoxygenase type I in transgenic rabbits increases the levels of endogenous lipoxin $\mathrm{A}_{4}$, which leads to prevention of periodontal inflammation as well as reduction of accelerated inflammatory events that contribute to atherosclerotic changes (Shen et al., 1996; Serhan et al., 2008).

\section{CONCLUSION}

Oral inflammatory processes involve microbial etiologic factors induce a series of host responses that mediate an inflammatory cascade of events in an attempt to protect and/or heal the tissues. It is becoming clear that the phenotype of the macrophage is central to determining the fate of the lesion; resolving; or chronic. Since the response of the macrophage is essential to health and disease, it is important to achieve a more complete understanding of the molecular events in this complex system. It is now becoming apparent that innate immune system cells are the determinants of the fate of the tissues and organs and are more than just transient, and their role is not limited to engulfing the invading microbes. Neutrophils and monocyte/macrophages are the key cells of the host response where their role go beyond the "defense" and is involved in the entire armamentarium of tissue homeostasis where protection, healing-repair, and regeneration are encoded.

\section{ACKNOWLEDGMENTS}

This work was supported by the USPHS grants DE15566, DE16191 (Thomas E. Van Dyke), DE018917 (Hatice Hasturk), and DE020906 (Alpdogan Kantarci).
LPS receptor on human monocytes. J. Endotoxin Res. 7, 281-286.

Amar, S., Zhou, Q., ShaikDasthagirisaheb, Y., and Leeman, S. (2007). Diet-induced obesity in mice causes changes in immune responses and bone loss manifested by bacterial challenge. Proc. Natl. Acad. Sci. U.S.A. 104, 20466-20471.

Anderson, D. M., Maraskovsky, E., Billingsley, W. L., Dougall, W. C., Tometsko, M. E., Roux, E. R., Teepe, M. C., DuBose, R. F., Cosman, D., and Galibert, L. (1997). A homologue of the TNF receptor and its ligand enhance $\mathrm{T}$-cell growth and dendritic-cell function. Nature 390, 175-179.

Anderson, K. V. (2000). Toll signaling pathways in the innate immune response. Curr. Opin. Immunol. 12, 13-19.
Ara, T., Kurata, K., Hirai, K., Uchihashi, T., Uematsu, T., Imamura, Y., Furusawa, K., Kurihara, S., and Wang, P. L. (2009). Human gingival fibroblasts are critical in sustaining inflammation in periodontal disease. $J$. Periodont. Res. 44, 21-27.

Arbes, S. J. Jr., Slade, G. D., and Beck, J. D. (1999). Association between extent of periodontal attachment loss and self-reported history of heart attack: an analysis of NHANES III data. $J$. Dent. Res. 78, 1777-1782.

Bakthavatchalu, V., Meka, A., Mans, J. J., Sathishkumar, S., Lopez, M. C., Bhattacharyya, I., Boyce, B. F., Baker, H. V., Lamont, R. J., and Ebersole, J. L., Kesavalu, L. (2011). Polymicrobial periodontal pathogen transcriptomes in calvarial bone and soft tissue. Mol. Oral Microbiol. 26, 303-320.
Baldwin, A. S. Jr. (1996). The NF-kappa B and I kappa B proteins: new discoveries and insights. Annu. Rev. Immunol. 14, 649-683.

Balkwill, F. R., and Burke, F. (1989). The cytokine network. Immunol. Today 10, 299-304.

Bannenberg, G. L., Chiang, N., Ariel, A., Arita, M., Tjonahen, E., Gotlinger, K. H., Hong, S., and Serhan, C. N. (2005). Molecular circuits of resolution: formation and actions of resolvins and protectins. J. Immunol. 174, 4345-4355.

Behl, Y., Siqueira, M., Ortiz, J., Li, J., Desta, T., Faibish, D., and Graves, D. T. (2008). Activation of the acquired immune response reduces coupled bone formation in response to a periodontal pathogen. J. Immunol. 181, 8711-8718. 
Bendre, M. S., Montague, D. C., Peery, T., Akel, N. S., Gaddy, D., and Suva, L. J. (2003). Interleukin-8 stimulation of osteoclastogenesis and bone resorption is a mechanism for the increased osteolysis of metastatic bone disease. Bone 33, 28-37.

Bhatavadekar, N. B., and Williams, R. C. (2009). Modulation of the host inflammatory response in periodontal disease management: exciting new directions. Int. Dent. J. 59, 305-308.

Birkedal-Hansen, H. (1993). Role of matrix metalloproteinases in human periodontal diseases. J. Periodontol. 64(Suppl.), 474-484.

Brown, J. M., Zhang, J., and Keller, E. T. (2004). Opg, RANKl, and RANK in cancer metastasis: expression and regulation. Cancer Treat. Res. 118, 149-172.

Cao, Z., Henzel, W. J., and Gao, X. (1996). IRAK: a kinase associated with the interleukin-1 receptor. Science 271, 1128-1131.

Chaudhary, P. M., Ferguson, C., Nguyen, V., Nguyen, O., Massa, H. F., Eby, M., Jasmin, A., Trask, B. J., Hood, L., and Nelson, P. S. (1998). Cloning and characterization of two Toll/Interleukin-1 receptor-like genes TIL3 and TIL4: evidence for a multi-gene receptor family in humans. Blood 91, 4020-4027.

Claria, J., Lee, M. H., and Serhan, C. N. (1996). Aspirin-triggered lipoxins (15-epi-LX) are generated by the human lung adenocarcinoma cell line (A549)-neutrophil interactions and are potent inhibitors of cell proliferation. Mol. Med. 2, 583-596.

Cook, D. N., Pisetsky, D. S., and Schwartz, D. A. (2004). Toll-like receptors in the pathogenesis of human disease. Nat. Immunol. 5, 975-979.

Czech, M. P., Lawrence, J. C. Jr., and Lynn, W. S. (1974). Evidence for the involvement of sulfhydryl oxidation in the regulation of fat cell hexose transport by insulin. Proc. Natl. Acad. Sci. U.S.A. 71, 4173-4177.

D’Ambrosio, D., Iellem, A., Bonecchi, R., Mazzeo, D., Sozzani, S., Mantovani, A., and Sinigaglia, F. (1998). Selective up-regulation of chemokine receptors CCR4 and CCR8 upon activation of polarized human type $2 \mathrm{Th}$ cells. J. Immunol. 161, 5111-5115.

de Waal Malefyt, R., Figdor, C. G., Huijbens, R., Mohan-Peterson S, Bennett, B., Culpepper, J., Dang, W., Zurawski, G., and de Vries, J. E. (1993). Effects of IL-13 on phenotype, cytokine production, and cytotoxic function of human monocytes.
Comparison with IL-4 and modulation by IFN-gamma or IL-10. J. Immunol. 151, 6370-6381.

Deshpande, R. G., Khan, M. B., and Genco, C. A. (1998). Invasion of aortic and heart endothelial cells by Porphyromonas gingivalis. Infect. Immun. 66, 5337-5343.

DeStefano, F., Anda, R. F., Kahn, H. S., Williamson, D. F., and Russell, C. M. (1993). Dental disease and risk of coronary heart disease and mortality. BMJ 306, 688-691.

Dietrich, J. W., Goodson, J. M., and Raisz, L. G. (1975). Stimulation of bone resorption by various prostaglandins in organ culture. Prostaglandins 10, 231-240.

Dinarello, C. A. (2000). Proinflammatory cytokines. Chest 118, 503-508.

Ding, Y., Kantarci, A., Hasturk, H., Trackman, P. C., Malabanan, A., and Van Dyke, T. E. (2007a). Activation of RAGE induces elevated $\mathrm{O}_{2}$ generation by mononuclear phagocytes in diabetes. J. Leukoc. Biol. 81, 520-527.

Ding, Y., Kantarci, A., Badwey, J. A., Hasturk, H., Malabanan, A., and Van Dyke, T. E. (2007b). Phosphorylation of pleckstrin increases proinflammatory cytokine secretion by mononuclear phagocytes in diabetes mellitus. J. Immunol. 179, 647-654.

Donati, M., Liljenberg, B., Zitzmann, N. U., and Berglundh, T. (2009). B-1a cells in experimental gingivitis in humans. J. Periodontol. 80, 1141-1145.

Dorn, B. R., Burks, J. N., Seifert, K. N., and Progulske-Fox, A. (2000). Invasion of endothelial and epithelial cells by strains of Porphyromonas gingivalis. FEMS Microbiol. Lett. 187, 139-144.

Duffield, J. S., Hong, S., Vaidya, V. S., Lu, Y., Fredman, G., Serhan, C. N., and Bonventre, J. V. (2006). Resolvin D series and protectin D1 mitigate acute kidney injury. J. Immunol. 177, 5902-5911.

Ebersole, J. L., Steffen, M. J., Holt, S. C., Kesavalu, L., Chu, L., and Cappelli, D. (2010). Systemic inflammatory responses in progressing periodontitis during pregnancy in a baboon model. Clin. Exp. Immunol. 162, 550-559.

Ebert, L. M., Schaerli, P., and Moser, B. (2005). Chemokine-mediated control of T cell traffic in lymphoid and peripheral tissues. Mol. Immunol.42, 799-809.

Esche, C., Stellato, C., and Beck, L. A. (2005). Chemokines: key players in innate and adaptive immunity. $J$. Invest. Dermatol. 125, 615-628.
Firth, J. D., Putnins, E. E., Larjava, H., and Uitto, V. J. (1997). Bacterial phospholipase $\mathrm{C}$ upregulates matrix metalloproteinase expression by cultured epithelial cells. Infect. Immun. 65, 4931-4936.

Fonseca, J. E., Santos, M. J., Canhão, H., and Choy, E. (2009). Interleukin-6 as a key player in systemic inflammation and joint destruction. Autoimmun. Rev. 8, 538-542.

Fujihara, M., Muroi, M., Muroi, Y., Ito, N., and Suzuki, T. (1993). Mechanism of lipopolysaccharidetriggered junB activation in a mouse macrophage-like cell line (J774). J. Biol. Chem. 268, 14898-14905.

Garlet, G. P. (2010). Destructive and protective roles of cytokines in periodontitis: a re-appraisal from host defense and tissue destruction viewpoints. J. Dent. Res. 89, 1349-1363.

Garlet, G. P., Cardoso, C. R., Campanelli, A. P., Ferreira, B. R., AvilaCampos, M. J., Cunha, F. Q., and Silva, J. S. (2007). The dual role of p55 tumour necrosis factor-alpha receptor in Actinobacillus actinomycetemcomitans-induced experimental periodontitis: host protection and tissue destruction. Clin. Exp. Immunol. 147, 128-138.

Garlet, G. P., Martins, W. Jr., Ferreira, B. R., Milanezi, C. M., and Silva, J. S. (2003). Patterns of chemokines and chemokine receptors expression in different forms of human periodontal disease. J. Periodont. Res. 38, 210-217.

Garlet, G. P., Martins, W. Jr., Fonseca, B. A., Ferreira, B. R., and Silva, J. S. (2004). Matrix metalloproteinases, their physiological inhibitors and osteoclast factors are differentially regulated by the cytokine profile in human periodontal disease. J. Clin. Periodontol. 31, 671-679.

Gegner, J. A., Ulevitch, R. J., and Tobias, P. S. (1995). Lipopolysaccharide (LPS) signal transduction and clearance. Dual roles for LPS binding protein and membrane CD14. J. Biol. Chem. 270, 5320-5325.

Gemmell, E., Carter, C. L., and Seymour, G. J. (2001). Chemokines in human periodontal disease tissues. Clin. Exp. Immunol. 125, 134-141.

Gemmell, E., Marshall, R. I., and Seymour, G. J. (1997). Cytokines and prostaglandins in immune homeostasis and tissue destruction in periodontal disease. Periodontol. 2000 14, 112-143.

Goodson, J. M., Dewhirst, F. E., and Brunetti, A. (1974). Prostaglandin E2 levels and human periodontal disease. Prostaglandins 6, 81-85.
Grassi, F., Cristino, S., Toneguzzi, S., Piacentini, A., Facchini, A., and Lisignoli, G. (2004). CXCL12 chemokine up-regulates bone resorption and MMP-9 release by human osteoclasts: CXCL12 levels are increased in synovial and bone tissue of rheumatoid arthritis patients. J. Cell. Physiol. 199, 244-251.

Grassi, F., Piacentini, A., Cristino, S., Toneguzzi, S., Cavallo, C., Facchini, A., and Lisignoli, G. (2003). Human osteoclasts express different CXC chemokines depending on cell culture substrate: molecular and immunocytochemical evidence of high levels of CXCL10 and CXCL12. Histochem. Cell Biol. 120, 391-400.

Graves, D. (2008). Cytokines that promote periodontal tissue destruction. J. Periodontol. 79(Suppl.), 1585-1591.

Graves, D. T., and Cochran, D. (2003). The contribution of interleukin-1 and tumor necrosis factor to periodontal tissue destruction. J. Periodontol. 74, 391-401.

Graves, D. T., Fine, D., Teng, Y. T., Van Dyke, T. E., and Hajishengallis, G. (2008). The use of rodent models to investigate host-bacteria interactions related to periodontal diseases. J. Clin. Periodontol. 35, 89-105.

Gu, L., Tseng, S., Horner, R. M., Tam, C., Loda, M., and Rollins, B. J. (2000). Control of $\mathrm{TH} 2$ polarization by the chemokine monocyte chemoattractant protein-1. Nature 404, 407-411.

Guha, M., and Mackman, N. (2001). LPS induction of gene expression in human monocytes. Cell. Signal. 13, 85-94.

Hajishengallis, G. (2010). Complement and periodontitis. Biochem. Pharmacol. 80, 1992-2001.

Hambleton, J., Weinstein, S. L., Lem, L., and DeFranco, A. L. (1996). Activation of c-Jun $\mathrm{N}$-terminal kinase in bacterial lipopolysaccharidestimulated macrophages. Proc. Natl. Acad. Sci. U.S.A. 93, 2774-2778.

Han, J., Ulevitch, R. J., Lee, J. D., and Bibbs, L. (1994). A MAP kinase targeted by endotoxin and hyperosmolarity in mammalian cells. Science 265, 808-811.

Hanada, T., and Yoshimura, A. (2002). Regulation of cytokine signaling and inflammation. Cytokine Growth Factor Rev. 13, 413-421.

Hanazawa, S., Kawata, Y., Takeshita, A., Kumada, H., Okithu, M., Tanaka, S., Yamamoto, Y., Masuda, T., Umemoto, T., and Kitano, S. (1993). Expression of monocyte chemoattractant 
protein 1 (MCP-1) in adult periodontal disease: increased monocyte chemotactic activity in crevicular fluids and induction of MCP-1 expression in gingival tissues. Infect. Immun. 61, 5219-5224.

Hansson, G. K. (2005). Inflammation, atherosclerosis, and coronary artery disease. N. Engl. J. Med. 352, 1685-1695.

Haraszthy, V. I., Zambon, J. J., Trevisan, M., Zeid, M., and Genco, R. J. (2000). Identification of periodontal pathogens in atheromatous plaques. J. Periodontol. 71, 1554-1560.

Harrell, J. C., and Stein, S. H. (1995). Prostaglandin E2 regulates gingival mononuclear cell immunoglobulin production. J. Periodontol. 66, 222-227.

Hasturk, H., Kantarci, A., GoguetSurmenian, E., Blackwood, A., Andry, C., Serhan, C. N., and Van Dyke, T. E. (2007). Resolvin E1 regulates inflammation at the cellular and tissue level and restores tissue homeostasis in vivo. I. Immunol. 179, 7021-7029.

Hasturk, H., Kantarci, A., Ohira, T., Arita, M., Ebrahimi, N., Chiang, N., Petasis, N. A., Levy, B. D., Serhan, C. N., and Van Dyke, T. E. (2006). RvE1 protects from local inflammation and osteoclast- mediated bone destruction in periodontitis. FASEB J. 20, 401-403.

Hasturk, H., Kantarci, A., and Van Dyke, T. E. (2012). Paradigm shift in the pharmacological management of periodontal diseases. Front. Oral Biol. 15, 160-176.

Haziot, A., Chen, S., Ferrero, E., Low, M. G., Silber, R., and Goyert, S. M. (1988). The monocyte differentiation antigen, CD14, is anchored to the cell membrane by a phosphatidylinositol linkage. J. Immunol. 141, 547-552.

Haziot, A., Ferrero, E., Köntgen, F., Hijiya, N., Yamamoto, S., Silver, J., Stewart, C. L., and Goyert, S. M. (1996). Resistance to endotoxin shock and reduced dissemination of gram- negative bacteria in CD14-deficient mice. Immunity 4, 407-414.

Henderson, B., Nair, S. P., Ward, J. M., and Wilson, M. (2003). Molecular pathogenicity of the oral opportunistic pathogen Actinobacillus actinomycetemcomitans. Annu. Rev. Microbiol. 57, 29-55.

Henry, M. T., McMahon, K., Mackarel, A. J., Prikk, K., Sorsa, T., Maisi, P., Sepper, R., Fitzgerald, M. X., and O'Connor, C. M. (2002). Matrix metalloproteinases and tissue inhibitor of metalloproteinase-1 in sarcoidosis and IPF. Eur. Respir. J. 20, 1220-1227.

Hoebe, K., Du, X., Georgel, P., Janssen, E., Tabeta, K., Kim, S. O., Goode, J., Lin, P., Mann, N., Mudd, S., Crozat, K., Sovath, S., Han, J., and Beutler, B. (2003). Identification of Lps2 as a key transducer of MyD88independent TIR signalling. Nature 424, 743-748.

Hofbauer, L. C., and Schoppet, M. (2004). Clinical implications of the osteoprotegerin/RANKL/RANK system for bone and vascular diseases. JAMA 292, 490-495.

Honore, P., Luger, N. M., Sabino, M. A., Schwei, M. J., Rogers, S. D., Mach, D. B., O'Keefe, P. F., Ramnaraine, M. L., Clohisy, D. R., and Mantyh, P. W. (2000). Osteoprotegerin blocks bone cancer-induced skeletal destruction, skeletal pain and painrelated neurochemical reorganization of the spinal cord. Nat. Med. 6 521-528.

Hsu, H., Lacey, D. L., Dunstan, C. R., Solovyev, I., Colombero, A., Timms, E., Tan, H.-L., Elliott, G., Kelley, M. J., Sarosi, I., Wang, L., Xia, X.-Z., Elliott, R., Chiu, L., Black, T., Scully, S., Capparelli, C., Morony, S., Shimamoto, G., Bass, M. B., and Boyle, W. J. (1999). Tumor necrosis factor receptor family member RANK mediates osteoclast differentiation and activation induced by osteoprotegerin ligand. Proc. Natl. Acad. Sci. U.S.A. 96, 3540-3545.

Hua, X. Y., Chen, P., Fox, A., and Myers, R. R. (1996). Involvement of cytokines in lipopolysaccharideinduced facilitation of CGRP release from capsaicin-sensitive nerves in the trachea: studies with interleukinlbeta and tumor necrosis factoralpha. J. Neurosci. 16, 4742-4748.

Iino, Y., and Hopps, R. M. (1984). The bone-resorbing activities in tissue culture of lipopolysaccharides from the bacteria Actinobacillus actinomycetemcomitans, Bacteroides gingivalis and Capnocytophaga ochracea isolated from human mouths. Arch. Oral Biol. 29, 59-63.

Inohara, N., and Nunez, G. (2003). NODs: intracellular proteins involved in inflammation and apoptosis. Nat. Rev. Immunol. 3, 371-382.

Iontcheva, I., Amar, S., Zawawi, K. H., Kantarci, A., and Van Dyke, T. E. (2004). Role for moesin in lipopolysaccharide-stimulated signal transduction. Infect. Immun. 72, 2312-2320.

Iwasaki, A., and Medzhitov, R. (2004). Toll-like receptor control of the adaptive immune responses. Nat. Immunol. 5, 987-995.

Jain, A., Batista, E. L. Jr., Serhan, C., Stahl, G. L., and Van Dyke, T. E. (2003). Role for periodontitis in the progression of lipid deposition in an animal model. Infect. Immun. 71, 6012-6018.

Janeway, C. A. Jr., and Medzhitov, R. (2002). Innate immune recognition. Annu. Rev. Immunol. 20, 197-216.

Jiang, Q., Akashi, S., Miyake, K., and Petty, H. R. (2000). Lipopolysaccharide induces physical proximity between CD14 and toll-like receptor 4 (TLR4) prior to nuclear translocation of NF-kappa B. J. Immunol. 165, 3541-3544.

Kabashima, H., Yoneda, M., Nagata, K., Hirofuji, T., and Maeda, K. (2002). The presence of chemokine (MCP-1, MIP-1alpha, MIP-1beta, IP-10, RANTES)-positive cells and chemokine receptor (CCR5, CXCR3)-positive cells in inflamed human gingival tissues. Cytokine 20, 70-77.

Kahari, V. M., and Saarialho-Kere, U. (1997). Matrix metalloproteinases in skin. Exp. Dermatol. 6, 199-213.

Kahari, V. M., and Saarialho-Kere, U. (1999). Matrix metalloproteinases and their inhibitors in tumour growth and invasion. Ann. Med. 31, 34-45.

Kaisho, T., and Akira, S. (2002). Tolllike receptors as adjuvant receptors. Biochim. Biophys. Acta 1589, 1-13.

Kantarci, A., Nseir, Z., Kim, Y. S. Sume, S. S., and Trackman, P. C. (2011). Loss of basement membrane integrity in human gingival overgrowth. J. Dent. Res. 90, 887-893.

Kantarci, A., and Van Dyke, T. E. (2003). Lipoxins in chronic inflammation. Crit. Rev. Oral Biol. Med. 14, 4-12.

Kawai, T., Matsuyama, T., Hosokawa, Y., Makihira, S., Seki, M., Karimbux, N. Y., Goncalves, R. B., Valverde, P., Dibart, S., Li, Y. P., Miranda, L. A., Ernst, C. W., Izumi, Y., and Taubman, M. A. (2006). B and T lymphocytes are the primary sources of RANKL in the bone resorptive lesion of periodontal disease. Am. J. Pathol. 169, 987-998.

Kawai, T., Takeuchi, O., Fujita, T., Inoue, J., Mühlradt, P. F., Sato, S., Hoshino, K., and Akira, S. (2001). Lipopolysaccharide stimulates the MyD88-independent pathway and results in activation of IFN-regulatory factor 3 and the expression of a subset of lipopolysaccharide-inducible genes. J. Immunol. 167, 5887-5894.

Kessler, J. A., and Freidin, M. (1993). Cytokines regulate substance $\mathrm{P}$ expression in sympathetic neurons. Regul. Pept. 46, 70-75.

Kiili, M., Cox, S. W., Chen, H. Y., Wahlgren, J., Maisi, P., Eley, B. M., Salo, T., and Sorsa, T. (2002). Collagenase-2 (MMP-8) and collagenase-3 (MMP-13) in adult periodontitis: molecular forms and levels in gingival crevicular fluid and immunolocalization in gingival tissue. J. Clin. Periodontol. 29, 224-232.

Kim, M. S., Day, C. J., Selinger, C. I., Magno, C. L., Stephens, S. R., and Morrison, N. A. (2006a). MCP-1-induced human osteoclastlike cells are tartrate-resistant acid phosphatase, NFATc1, and calcitonin receptor-positive but require receptor activator of NFkappaB ligand for bone resorption. J. Biol. Chem. 281, 1274-1285.

Kim, M. S., Magno, C. L., Day, C. J. and Morrison, N. A. (2006b). Induction of chemokines and chemokine receptors CCR2b and CCR4 in authentic human osteoclasts differentiated with RANKL and osteoclast like cells differentiated by MCP-1 and RANTES. J. Cell. Biochem. 97, 512-518.

Kindle, L., Rothe, L., Kriss, M., Osdoby, P., and Collin-Osdoby, P. (2006). Human microvascular endothelial cell activation by IL-1 and TNFalpha stimulates the adhesion and transendothelial migration of circulating human CD14+ monocytes that develop with RANKL into functional osteoclasts. J. Bone Miner. Res. 21, 193-206.

Knauper, V., Cowell, S., Smith, B., López-Otin C, O'Shea, M., Morris, H., Zardi, L., and Murphy, G. (1997) The role of the C-terminal domain of human collagenase-3 (MMP-13) in the activation of procollagenase3 , substrate specificity, and tissue inhibitor of metalloproteinase interaction. J. Biol. Chem. 272, 7608-7616.

Kong, Y. Y., Feige, U., Sarosi, I., Bolon, B., Tafuri, A., Morony, S., Capparelli, C., Li, J., Elliott, R., McCabe, S. Wong, T., Campagnuolo, G., Moran E., Bogoch, E. R., Van, G., Nguyen, L. T., Ohashi, P. S., Lacey, D. L., Fish, E., Boyle, W. J., and Penninger, J. M. (1999). Activated T cells regulate bone loss and joint destruction in adjuvant arthritis through osteoprotegerin ligand. Nature 402, 304-309.

Konttinen, Y. T., Salo, T., Hanemaaijer, R., Valleala, H., Sorsa, T., Sutinen, M., Ceponis, A., Xu, J. W., Santavirta, S., Teronen, O., and López-Otín, C. (1999). Collagenase-3 (MMP-13) and its activators in rheumatoid 
arthritis: localization in the pannushard tissue junction and inhibition by alendronate. Matrix Biol. 18, 401-412.

Krutzik, S. R., and Modlin, R. L. (2004). The role of Toll-like receptors in combating mycobacteria. Semin. Immunol. 16, 35-41.

Kumar, V. A., Abass, A. K., and Fausto, N. (2005). Pathologic Basis of Disease. Philadelphia: Elsevier Saunders.

Kwak, H. B., Lee, S. W., Jin, H. M., Ha, H., Lee, S. H., Takeshita, S., Tanaka, S., Kim, H. M., Kim, H. H., and Lee, Z. H. (2005). Monokine induced by interferon-gamma is induced by receptor activator of nuclear factor kappa B ligand and is involved in osteoclast adhesion and migration. Blood 105, 2963-2969.

Kwan Tat, S., Padrines, M., Théoleyre, S., Heymann, D., and Fortun, Y. (2004). IL-6, RANKL, TNF-alpha/IL-1: interrelations in bone resorption pathophysiology. Cytokine Growth Factor Rev. 15, 49-60.

Lacey, D. L., Timms, E., Tan, H. L., Kelley, M. J., Dunstan, C. R., Burgess, T., Elliott, R., Colombero, A., Elliott, G., Scully, S., Hsu, H., Sullivan, J., Hawkins, N., Davy, E., Capparelli, C., Eli, A., Qian, Y. X., Kaufman, S., Sarosi, I., Shalhoub, V., Senaldi, G., Guo, J., Delaney, J., and Boyle, W. J. (1998). Osteoprotegerin ligand is a cytokine that regulates osteoclast differentiation and activation. Cell 93, 165-176.

Lalla, E., Lamster, I. B., Hofmann, M. A., Bucciarelli, L., Jerud, A. P., Tucker, S., Lu, Y., Papapanou, P. N., and Schmidt, A. M. (2003). Oral infection with a periodontal pathogen accelerates early atherosclerosis in apolipoprotein E-null mice. Arterioscler. Thromb. Vasc. Biol. 23, 1405-1411.

Lambrecht, B. N., Germonpré, P. R., Everaert, E. G., Carro-Muino I, De Veerman, M., de Felipe, C., Hunt, S. P., Thielemans, K., Joos, G. F., and Pauwels, R. A. (1999). Endogenously produced substance $\mathrm{P}$ contributes to lymphocyte proliferation induced by dendritic cells and direct TCR ligation. Eur. J. Immunol. 29, 3815-3825.

Lean, J. M., Murphy, C., Chambers, T. J., and Lean, J. M. (2002). CCL9/MIP-1gamma and its receptor CCR1 are the major chemokine ligand/receptor species expressed by osteoclasts. J. Cell. Biochem. 87, 386-393.

Lee, W., Aitken, S., Sodek, J., and McCulloch, C. A. (1995). Evidence of a direct relationship between neutrophil collagenase activity and periodontal tissue destruction in vivo: role of active enzyme in human periodontitis. J. Periodont. Res. 30, 23-33.

Levy, B. D., Clish, C. B., Schmidt, B., Gronert, K., and Serhan, C. N. (2001). Lipid mediator class switching during acute inflammation: signals in resolution. Nat. Immunol. 2, 612-619.

Lewis, R. A. (1990). Interactions of eicosanoids and cytokines in immune regulation. $A d v$. Prostaglandin Thromboxane Leukot. Res. 20, 170-178.

Li, Q., Yu, H., Zinna, R., Martin, K., Herbert, B., Liu, A., and Rossa, C. Jr., Kirkwood, K. L. (2011). Silencing mitogen-activated protein kinaseactivated protein kinase-2 arrests inflammatory bone loss. J. Pharmacol. Exp. Ther. 336, 633-642.

Lieb, K., Fiebich, B. L., Busse-Grawitz, M., Hüll, M., Berger, M., and Bauer, J. (1996). Effects of substance P and selected other neuropeptides on the synthesis of interleukin-1 beta and interleukin-6 in human monocytes: a re-examination. J. Neuroimmunol. 67, 77-81.

Lisignoli, G., Cristino, S., Toneguzzi, S., Grassi, F., Piacentini, A., Cavallo, C., Facchini, A., and Mariani, E. (2004). IL1beta and TNFalpha differently modulate CXCL13 chemokine in stromal cells and osteoblasts isolated from osteoarthritis patients: evidence of changes associated to cell maturation. Exp. Gerontol. 39, 659-665.

Lisignoli, G., Toneguzzi, S., Piacentini, A., Cristino, S., Grassi, F., Cavallo, C., and Facchini, A. (2006). CXCL12 (SDF-1) and CXCL13 (BCA-1) chemokines significantly induce proliferation and collagen type I expression in osteoblasts from osteoarthritis patients. J. Cell. Physiol. 206, 78-85.

Liu, Y. C., Lerner, U. H., and Teng, Y. T. (2000). Cytokine responses against periodontal infection: protective and destructive roles. Periodontol. 2000 52, 163-206.

Loning, T., Albers, H. K., Lisboa, B. P., Burkhardt, A., and Caselitz, J. (1980). Prostaglandin E and the local immune response in chronic periodontal disease. Immunohistochemical and radioimmunological observations. J. Periodont. Res. 15, 525-535.

Lundy, F. T., and Linden, G. J. (2004). Neuropeptides and neurogenic mechanisms in oral and periodontal inflammation. Crit. Rev. Oral Biol. Med. 15, 82-98.
MacDonald, K. P., Rowe, V., Bofinger, H. M., Thomas, R., Sasmono, T., Hume, D. A., and Hill, G. R. (2005). The colony-stimulating factor 1 receptor is expressed on dendritic cells during differentiation and regulates their expansion. J. Immunol. 175, 1399-1405.

Maddox, J. F., Hachicha, M., Takano, T., Petasis, N. A., Fokin, V. V., and Serhan, C. N. (1997). Lipoxin A4 stable analogs are potent mimetics that stimulate human monocytes and THP-1 cells via a G-proteinlinked lipoxin A4 receptor. J. Biol. Chem. 272, 6972-6978.

Maddox, J. F., and Serhan, C. N. (1996). Lipoxin A4 and B4 are potent stimuli for human monocyte migration and adhesion: selective inactivation by dehydrogenation and reduction. J. Exp. Med. 183, 137-146.

Mahamed, D. A., Marleau, A., Alnaeeli, M., Singh, B., Zhang, X., Penninger J. M., and Teng, Y. T. (2005). G() anaerobes-reactive CD4+ T-cells trigger RANKL-mediated enhanced alveolar bone loss in diabetic NOD mice. Diabetes 54, 1477-1486.

Makela, M., Larjava, H., Pirilä, E., Maisi, P., Salo, T., Sorsa, T., and Uitto, V. J. (1999). Matrix metalloproteinase 2 (gelatinase A) is related to migration of keratinocytes. Exp. Cell Res. 251, 67-78.

Marriott, I., and Bost, K. L. (1998). Substance P diminishes lipopolysaccharide and interferon-gamma-induced TGF-beta 1 production by cultured murine macrophages. Cell. Immunol. 183, 113-120.

Martin, T. J., and Sims, N. A. (2005) Osteoclast-derived activity in the coupling of bone formation to resorption. Trends. Mol. Med. 11, 76-81.

Martinez, F. O., Helming, L., and Gordon, S. (2009). Alternative activation of macrophages: an immunologic functional perspective. Annu. Rev. Immunol. 27, 451-483.

Mathur, A., Michalowicz, B., Castillo, M., and Aeppli, D. (1996). Interleukin-1 alpha, interleukin-8 and interferon-alpha levels in gingival crevicular fluid. J. Periodont. Res. 31, 489-495.

Mattila, K. J., Nieminen, M. S., Valtonen, V. V., Rasi, V. P., Kesäniemi, Y. A., Syrjälä, S. L., Jungell, P. S., Isoluoma, M., Hietaniemi, K., and Jokinen, M. J. (1989). Association between dental health and acute myocardial infarction. BMJ 298, 779-781.

McCauley, L. K., and Nohutcu, R. M. (2002). Mediators of periodontal osseous destruction and remodeling: principles and implications for diagnosis and therapy. J. Periodontol. 73 1377-1391.

McGillis, J. P., Humphreys, S., and Reid, S. (1991). Characterization of functional calcitonin gene-related peptide receptors on rat lymphocytes. $J$. Immunol. 147, 3482-3489.

Means, T. K., Golenbock, D. T., and Fenton, M. J. (2000). The biology of Toll-like receptors. Cytokine Growth Factor Rev. 11, 219-232.

Medzhitov, R., and Janeway, C. A. Jr. (1997). Innate immunity: the virtues of a nonclonal system of recognition. Cell 91, 295-298.

Medzhitov, R., Preston-Hurlburt, P., and Janeway, C. A. Jr. (1997). A human homologue of the Drosophila Toll protein signals activation of adaptive immunity. Nature 388, 394-397.

Medzhitov, R., Preston-Hurlburt, P., Kopp, E., Stadlen, A., Chen, C., Ghosh, S., and Janeway, C. A. Jr. (1998). MyD88 is an adaptor protein in the hToll/IL-1 receptor family signaling pathways. Mol. Cell 2, 253-258.

Mendieta, C. F., Reeve, C. M., and Romero, J. C. (1985). Biosynthesis of prostaglandins in gingiva of patients with chronic periodontitis. J. Periodontol. 56, 44-47.

Mishima, E., and Sharma, A. (2011). Tannerella forsythia invasion in oral epithelial cells requires phosphoinositide 3-kinase activation and clathrin-mediated endocytosis. Microbiology 157(Pt 8), 2382-2391.

Mizuno, A., Amizuka, N., Irie, K., Murakami, A., Fujise, N., Kanno, T., Sato, Y., Nakagawa, N., Yasuda, H., Mochizuki, S., Gomibuchi, T., Yano, K., Shima, N., Washida, N., Tsuda, E., Morinaga, T., Higashio, K., and Ozawa, H. (1998). Severe osteoporosis in mice lacking osteoclastogenesis inhibitory factor/osteoprotegerin. Biochem. Biophys. Res. Commun. 247, 610-615.

Morse, L., Teng, Y. D., Pham, L., Newton, K., Yu, D., Liao, W. L., Kohler, T., Müller, R., Graves, D., Stashenko, P., and Battaglino, R. (2008). Spinal cord injury causes rapid osteoclastic resorption and growth plate abnormalities in growing rats (SCIinduced bone loss in growing rats). Osteoporos. Int. 19, 645-652.

Moser, B., Wolf, M., Walz, A., and Loetscher, P. (2004). Chemokines: multiple levels of leukocyte migration control. Trends Immunol. 25, 75-84.

Muroi, M., Muroi, Y., Yamamoto, K., and Suzuki, T. (1993). Influence of 3' half-site sequence of NFkappa $\mathrm{B}$ motifs on the binding 
of lipopolysaccharide-activatable macrophage NF-kappa B proteins. J. Biol. Chem. 268, 19534-19539.

Musacchio, E., Valvason, C., Botsios, C., Ostuni, F., Furlan, A., Ramonda, R., Modesti, V., Sartori, L., and Punzi, L. (2009). The tumor necrosis factor\{alpha\}-blocking agent infliximab inhibits interleukin lbeta (IL-1beta) and IL-6 gene expression in human osteoblastic cells. J. Rheumatol. 36, 1575-1579.

Muzio, M., Natoli, G., Saccani, S., Levrero, M., and Mantovani, A. (1998). The human toll signaling pathway: divergence of nuclear factor kappaB and JNK/SAPK activation upstream of tumor necrosis factor receptorassociated factor 6 (TRAF6). J. Exp. Med. 187, 2097-2101.

Nassar, H., Kantarci, A., and van Dyke, T. E. (2007). Diabetic periodontitis: a model for activated innate immunity and impaired resolution of inflammation. Periodontol. 2000 $43,233-244$

Offenbacher, S., Beck, J. D., Jared, H. L., Mauriello, S. M., Mendoza, L. C., Couper, D. J., Stewart, D. D., Murtha, A. P., Cochran, D. L., Dudley, D. J., Reddy, M. S., Geurs, N. C., Hauth, J. C., and Maternal Oral Therapy to Reduce Obstetric Risk (MOTOR) Investigators. (2009). Effects of periodontal therapy on rate of preterm delivery: a randomized controlled trial. Obstet. Gynecol. 114, 551-559.

Offenbacher, S., and Salvi, G. E. (1999). Induction of prostaglandin release from macrophages by bacterial endotoxin. Clin. Infect. Dis. 28, 505-513.

Okada, N., Kobayashi, M., Mugikura, K., Okamatsu, Y., Hanazawa, S., Kitano, S., and Hasegawa, K. (1997). Interleukin-6 production in human fibroblasts derived from periodontal tissues is differentially regulated by cytokines and a glucocorticoid. $J$. Periodont. Res. 32, 559-569.

Okamatsu, Y., Kim, D., Battaglino, R., Sasaki, H., Späte, U., and Stashenko, P. (2004). MIP-1 gamma promotes receptor-activator-of-NFkappa-B-ligand-induced osteoclast formation and survival. J. Immunol. 173, 2084-2090.

Opree, A., and Kress, M. (2000). Involvement of the proinflammatory cytokines tumor necrosis factor-alpha, IL-1 beta, and IL-6 but not IL-8 in the development of heat hyperalgesia: effects on heatevoked calcitonin gene-related peptide release from rat skin. J. Neurosci. 20, 6289-6293.

Pacher, P., Obrosova, I. G., Mabley, J. G., and Szabó, C. (2005). Role of nitrosative stress and peroxynitrite in the pathogenesis of diabetic complications. Emerging new therapeutical strategies. Curr. Med. Chem. 12, 267-275.

Page, R. C., and Schroeder, H. E. (1976). Pathogenesis of inflammatory periodontal disease. A summary of current work. Lab Invest. 34, 235-249.

Paigen, B., Holmes, P. A., Mitchell, D., and Albee, D. (1987a). Comparison of atherosclerotic lesions and HDL-lipid levels in male, female, and testosterone-treated female mice from strains $\mathrm{C} 57 \mathrm{BL} / 6, \mathrm{BALB} / \mathrm{c}$, and C3H. Atherosclerosis 64, 215-221.

Paigen, B., Mitchell, D., Reue, K., Morrow, A., Lusis, A. J., and LeBoeuf, R. C. (1987b). Ath-1, a gene determining atherosclerosis susceptibility and high density lipoprotein levels in mice. Proc. Natl. Acad. Sci. U.S.A. 84, 3763-3767.

Paquette, D. W., Madianos, P., Offenbacher, S., Beck, J. D., and Williams, R. C. (1999). The concept of "risk" and the emerging discipline of periodontal medicine. J. Contemp. Dent. Pract. 1, 1-8.

Payne, J. B., Reinhardt, R. A., Masada, M. P., DuBois, L. M., and Allison, A. C. (1993). Gingival crevicular fluid IL-8: correlation with local IL1 beta levels and patient estrogen status. J. Periodont. Res. 28(6 Pt 1), 451-453.

Peschon, J. J., Torrance, D. S., Stocking, K. L., Glaccum, M. B., Otten, C., Willis, C. R., Charrier, K., Morrissey, P. J., Ware, C. B., and Mohler, K. M. (1998). TNF receptor-deficient mice reveal divergent roles for $\mathrm{p} 55$ and p75 in several models of inflammation. J. Immunol. 160, 943-952.

Pihlstrom, B. L., Michalowicz, B. S., and Johnson, N. W. (2005). Periodontal diseases. Lancet 366, 1809-1820.

Poltorak, A., Ricciardi-Castagnoli, P., Citterio, S., and Beutler, B. (2000). Physical contact between lipopolysaccharide and toll-like receptor 4 revealed by genetic complementation. Proc. Natl. Acad. Sci. U.S.A. 97, 2163-2167.

Pruss, H., Kopp, M. A., Brommer, B., Gatzemeier, N., Laginha, I., Dirnagl, U., and Schwab, J. M. (2011). Nonresolving aspects of acute inflammation after spinal cord injury (SCI): indices and resolution plateau. Brain Pathol. 21, 652-660.

Putnins, E. E., Firth, J. D., and Uitto, V. J. (1996). Stimulation of collagenase (matrix metalloproteinase-1) synthesis in histiotypic epithelial cell culture by heparin is enhanced by keratinocyte growth factor. Matrix Biol. 15, 21-29.
Qi, M., Miyakawa, H., and Kuramitsu, H. K. (2003). Porphyromonas gingivalis induces murine macrophage foam cell formation. Microb. Pathog. 35, 259-267.

Quesniaux, V., Fremond, C., Jacobs, M., Parida, S., Nicolle, D., Yeremeev, V., Bihl, F., Erard, F., Botha, T., Drennan, M., Soler, M. N., Le Bert, M., Schnyder, B., and Ryffel, B. (2004). Toll-like receptor pathways in the immune responses to mycobacteria. Microbes Infect. 6, 946-959.

Raschi, E., Testoni, C., Bosisio, D. Borghi, M. O., Koike, T., Mantovani, A., and Meroni, P. L. (2003). Role of the MyD88 transduction signaling pathway in endothelial activation by antiphospholipid antibodies. Blood 101, 3495-3500.

Richards, D., and Rutherford, R. B. (1988). The effects of interleukin 1 on collagenolytic activity and prostaglandin-E secretion by human periodontal-ligament and gingival fibroblast. Arch. Oral Biol. 33, 237-243.

Ridker, P. M., Hennekens, C. H., Buring J. E., and Rifai, N. (2000). C-reactive protein and other markers of inflammation in the prediction of cardiovascular disease in women. N. Engl. J. Med. 342, 836-843.

Rock, F. L., Hardiman, G., Timans, J. C., Kastelein, R. A., and Bazan, J. F. (1998). A family of human receptors structurally related to Drosophila Toll. Proc. Natl. Acad. Sci. U.S.A. 95, 588-593.

Rodan, G. A., and Martin, T. J. (1981). Role of osteoblasts in hormonal control of bone resorption - a hypothesis. Calcif. Tissue Int. 33, 349-351.

Ross, R. (1993). The pathogenesis of atherosclerosis: a perspective for the 1990s. Nature 362, 801-809.

Rossi, D., and Zlotnik, A. (2000). The biology of chemokines and their receptors. Annu. Rev. Immunol. 18 217-242.

Rot, A., and von Andrian, U. H. (2004). Chemokines in innate and adaptive host defense: basic chemokinese grammar for immune cells. Annu. Rev. Immunol. 22, 891-928.

Saito, S., Rosol, T. J., Saito, M., Ngan, P. W., Shanfeld, J., and Davidovitch, Z. (1990a). Bone-resorbing activity and prostaglandin $\mathrm{E}$ produced by human periodontal ligament cells in vitro. J. Bone Miner. Res. 5, 1013-1018.

Saito, S., Saito, M., Ngan, P., Lanese, R., Shanfeld, J., and Davidovitch, Z. (1990b). Effects of parathyroid hormone and cytokines on prostaglandin E synthesis and bone resorption by human periodontal ligament fibroblasts. Arch. Oral Biol. 35, 845-855.

Sallusto, F., Lanzavecchia, A., and Mackay, C. R. (1998). Chemokines and chemokine receptors in $\mathrm{T}$ cell priming and Th1/Th2-mediated responses. Immunol. Today 19, 568-574.

Sanak, M., Levy, B. D., Clish, C. B. Chiang, N., Gronert, K., Mastalerz, L., Serhan, C. N., and Szczeklik, A. (2000). Aspirin-tolerant asthmatics generate more lipoxins than aspirinintolerant asthmatics. Eur. Respir. J. 16, 44-49.

Sato, N., Takahashi, N., Suda, K., Nakamura, M., Yamaki, M., Ninomiya, T., Kobayashi, Y., Takada, H., Shibata, K., Yamamoto, M., Takeda, K., Akira, S., Noguchi, T., and Udagawa, N. (2004). MyD88 but not TRIF is essential for osteoclastogenesis induced by lipopolysaccharide, diacyl lipopeptide, and IL-1alpha. J. Exp. Med. 200, 601-611.

Sato, S., Takeuchi, O., Fujita, T., Tomizawa, H., Takeda, K., and Akira S. (2002). A variety of microbial components induce tolerance to lipopolysaccharide by differentially affecting MyD88-dependent and -independent pathways. Int. Immunol. 14, 783-791.

Schif-Zuck, S., Gross, N., Assi, S., Rostoker, R., Serhan, C. N., and Ariel, A. (2011). Saturated-efferocytosis generates pro-resolving CD11b low macrophages: modulation by resolvins and glucocorticoids. Eur. J. Immunol. 41, 366-379.

Schumann, R. R., Leong, S. R., Flaggs, G. W., Gray, P. W., Wright, S. D., Mathison, J. C., Tobias, P. S., and Ulevitch, R. J. (1990). Structure and function of lipopolysaccharide binding protein. Science 249, 1429-1431.

Schwab, J. M., Chiang, N., Arita, M., and Serhan, C. N. (2007). Resolvin E1 and protectin D1 activate inflammation-resolution programmes. Nature 447, 869-874.

Serhan, C. N. (2004). A search for endogenous mechanisms of antiinflammation uncovers novel chemical mediators: missing links to resolution. Histochem. Cell Biol. 122, 305-321.

Serhan, C. N. (2010). Novel lipid mediators and resolution mechanisms in acute inflammation: to resolve or not? Am. J. Pathol. 177, 1576-1591.

Serhan, C. N., and Chiang, N. (2008). Endogenous pro-resolving and antiinflammatory lipid mediators: a new pharmacologic genus. Br. J. Pharmacol. 153(Suppl. 1), S200-S215.

Serhan, C. N., Chiang, N., Arita, M. and Serhan, C. N. (2007). Resolution 
of inflammation: state of the art, definitions and terms. FASEB J. 21, 325-332.

Serhan, C. N., Chiang, N., and Van Dyke, T. E. (2008). Resolving inflammation: dual anti-inflammatory and pro-resolution lipid mediators. Nat. Rev. Immunol. 8, 349-361.

Serhan, C. N., Fiore, S., Brezinski, D. A., and Lynch, S. (1993). Lipoxin A4 metabolism by differentiated HL60 cells and human monocytes: conversion to novel 15-oxo and dihydro products. Biochemistry 32, 6313-6319.

Serhan, C. N., Gotlinger, K., Hong, S., and Arita, M. (2004). Resolvins, docosatrienes, and neuroprotectins, novel omega-3-derived mediators, and their aspirin-triggered endogenous epimers: an overview of their protective roles in catabasis. Prostaglandins Other Lipid Mediat. 73, 155-172.

Serhan, C. N., Jain, A., Marleau, S., Clish, C., Kantarci, A., Behbehani, B., Colgan, S. P., Stahl, G. L., Merched, A., Petasis, N. A., Chan, L., and Van Dyke, T. E. (2003). Reduced inflammation and tissue damage in transgenic rabbits overexpressing 15-lipoxygenase and endogenous anti-inflammatory lipid mediators. J. Immunol. 171, 6856-6865.

Serhan, C. N., Maddox, J. F., Petasis, N. A., Akritopoulou-Zanze, I., Papayianni, A., Brady, H. R., Colgan, S. P., and Madara, J. L. (1995). Design of lipoxin A4 stable analogs that block transmigration and adhesion of human neutrophils. Biochemistry 34, 14609-14615.

Seymour, G. J. (1991). Importance of the host response in the periodontium. J. Clin. Periodontol. 18, 421-426.

Seymour, G. J., and Gemmell, E. (2001). Cytokines in periodontal disease: where to from here? Acta Odontol. Scand. 59, 167-173.

Shen, J., Herderick, E., Cornhill, J. F., Zsigmond, E., Kim, H. S., Kühn, H., Guevara, N. V., and Chan, L. (1996). Macrophage-mediated 15-lipoxygenase expression protects against atherosclerosis development. J. Clin. Invest. 98, 2201-2208.

Singh, A., Wyant, T., Anaya-Bergman, C., Aduse-Opoku, J., Brunner, J., Laine, M. L., Curtis, M. A., and Lewis, J. P. (2011). The capsule of Porphyromonas gingivalis leads to a reduction in the host inflammatory response, evasion of phagocytosis, and increase in virulence. Infect. Immun. 79, 4533-4542.
Socransky, S. S., and Haffajee, A. D. (2005). Periodontal microbial ecology. Periodontol. 2000 38, 135-187.

Song, L., Asgharzadeh, S., Salo, J., Engell, K., Wu, H. W., Sposto, R., Ara, T., Silverman, A. M., DeClerck, Y. A., Seeger, R. C., and Metelitsa, L. S. (2009). Valpha24-invariant NKT cells mediate antitumor activity via killing of tumor-associated macrophages. J. Clin. Invest. 119, 1524-1536.

Sorsa, T., Ding, Y. L., Ingman, T., Salo, T., Westerlund, U., Haapasalo, M., Tschesche, H., and Konttinen, Y. T. (1995). Cellular source, activation and inhibition of dental plaque collagenase. J. Clin. Periodontol. 22, 709-717.

Sorsa, T., Tjäderhane, L., Konttinen, Y. T., Lauhio, A., Salo, T., Lee, H. M., Golub, L. M., Brown, D. L., and Mäntylä, P. (2006). Matrix metalloproteinases: contribution to pathogenesis, diagnosis and treatment of periodontal inflammation. Ann. Med. 38, 306-321.

Sume, S. S., Kantarci, A., Lee, A., Hasturk, H., and Trackman, P. C. (2010). Epithelial to mesenchymal transition in gingival overgrowth. Am. J. Pathol. 177, 208-218.

Swantek, J. L., Tsen, M. F., Cobb, M. H., and Thomas, J. A. (2000). IL1 receptor-associated kinase modulates host responsiveness to endotoxin. J. Immunol. 164, 4301-4306.

Takagi, M., Konttinen, Y. T., Kemppinen, P., Sorsa, T., Tschesche, H., Bläser, J., Suda, A., and Santavirta, S. (1995). Tissue inhibitor of metalloproteinase 1, collagenolytic and gelatinolytic activity in loose hip endoprosthesis. J. Rheumatol. 22, 2285-2290.

Takashiba, S., Takigawa, M., Takahashi, K., Myokai, F., Nishimura, F., Chihara, T., Kurihara, H., Nomura, Y., and Murayama, Y. (1992). Interleukin-8 is a major neutrophil chemotactic factor derived from cultured human gingival fibroblasts stimulated with interleukin-1 beta or tumor necrosis factor alpha. Infect. Immun. 60, 5253-5258.

Takeda, K., Kaisho, T., and Akira, S. (2003). Toll-like receptors. Annu. Rev. Immunol. 21, 335-376.

Takigawa, M., Takashiba, S., Myokai, F., Takahashi, K., Arai, H., Kurihara, H., and Murayama, Y. (1994). Cytokine-dependent synergistic regulation of interleukin-8 production from human gingival fibroblasts. $J$. Periodontol. 65, 1002-1007.

Tanaka, S., Takahashi, N., Udagawa, N., Tamura, T., Akatsu, T., Stanley, E. R., Kurokawa, T., and Suda, T. (1993).
Macrophage colony-stimulating factor is indispensable for both proliferation and differentiation of osteoclast progenitors. J. Clin. Invest. 91, 257-263.

Tang, L., Zhou, X. D., Wang, Q., Zhang, L., Wang, Y., Li, X. Y., and Huang, D. M. (2011). Expression of TRAF6 and pro-inflammatory cytokines through activation of TLR2, TLR4, NOD1, and NOD2 in human periodontal ligament fibroblasts. Arch. Oral Biol. 56, 1064-1072.

Taubman, M. A., Kawai, T., and Han, X. (2007). The new concept of periodontal disease pathogenesis requires new and novel therapeutic strategies. J. Clin. Periodontol. 34 367-369.

Terricabras, E., Benjamim, C., and Godessart, N. (2004). Drug discovery and chemokine receptor antagonists: eppur si muove! Autoimmun. Rev. 3, 550-556.

The American Academy of Periodontology Academy Report. (1999). The pathogenesis of periodontal diseases. J. Periodontol. 70, 457-470.

Theill, L. E., Boyle, W. J., and Penninger, J. M. (2002). RANK-L and RANK: $\mathrm{T}$ cells, bone loss, and mammalian evolution. Annu. Rev. Immunol. 20, 795-823.

Tohme, Z. N., Amar, S., and Van Dyke, T. E. (1999). Moesin functions as a lipopolysaccharide receptor on human monocytes. Infect. Immun. 67, 3215-3220.

Tracey, K. J. (2002). The inflammatory reflex. Nature 420, 853-859.

Uehara, A., and Takada, H. (2007). Functional TLRs and NODs in human gingival fibroblasts. J. Dent. Res. 86, 249-254.

Uitto, V. J., Airola, K., Vaalamo, M., Johansson, N., Putnins, E. E., Firth, J. D., Salonen, J., López-Otín, C., Saarialho-Kere, U., and Kähäri, V. M. (1998). Collagenase-3 (matrix metalloproteinase-13) expression is induced in oral mucosal epithelium during chronic inflammation. Am. J. Pathol. 152, 1489-1499.

Uitto, V. J., Overall, C. M., and McCulloch, C. (2003). Proteolytic host cell enzymes in gingival crevice fluid. Periodontol. 2000 31, 77-104.

Ulevitch, R. J., and Tobias, P. S. (1995). Receptor-dependent mechanisms of cell stimulation by bacterial endotoxin. Annu. Rev. Immunol. 13, 437-457.

Van Dyke, T. E. (2007). Control of inflammation and periodontitis. Periodontol. 2000, 45, 158-166.

Van Dyke, T. E. (2008). The management of inflammation in periodontal disease. J. Periodontol. 79(Suppl.), 1601-1608.

Van Dyke, T. E., and Serhan, C. N. (2003). Resolution of inflammation: a new paradigm for the pathogenesis of periodontal diseases. J. Dent. Res. 82, 82-90.

Vergnolle, N. (1999). Proteinaseactivated receptor-2-activating peptides induce leukocyte rolling, adhesion, and extravasation in vivo. J. Immunol. 163, 5064-5069.

Virag, L., and Szabo, C. (2002). The therapeutic potential of poly(ADPribose) polymerase inhibitors. Pharmacol. Rev. 54, 375-429.

Visse, R., and Nagase, H. (2003). Matrix metalloproteinases and tissue inhibitors of metalloproteinases: structure, function, and biochemistry. Circ. Res. 92, 827-839.

Votta, B. J., White, J. R., Dodds, R. A., James, I. E., Connor, J. R., Lee-Rykaczewski E, Eichman, C. F., Kumar, S., Lark, M. W., and Gowen, M. (2000). CKbeta-8 [CCL23], a novel CC chemokine, is chemotactic for human osteoclast precursors and is expressed in bone tissues. $J$. Cell. Physiol. 183, 196-207.

Wahlgren, J., Salo, T., Teronen, O., Luoto, H., Sorsa, T., and Tjäderhane, L. (2002). Matrix metalloproteinase-8 (MMP-8) in pulpal and periapical inflammation and periapical rootcanal exudates. Int. Endod. J. 35, 897-904.

Wajant, H., Pfizenmaier, K., and Scheurich, P. (2003). Tumor necrosis factor signaling. Cell Death Differ. 10, 45-65.

Watters, T. M., Kenny, E. F., and O’Neill, L. A. (2007). Structure, function and regulation of the Toll/IL-1 receptor adaptor proteins. Immunol. Cell Biol. 85, 411-419.

Weinstein, S. L., Sanghera, J. S., Lemke, K., DeFranco, A. L., and Pelech, S. L. (1992). Bacterial lipopolysaccharide induces tyrosine phosphorylation and activation of mitogen-activated protein kinases in macrophages. $J$. Biol. Chem. 267, 14955-14962.

Wingrove, J. A., DiScipio, R. G., Chen, Z., Potempa, J., Travis, J., and Hugli, T. E. (1992). Activation of complement components C3 and C5 by a cysteine proteinase (gingipain-1) from Porphyromonas (Bacteroides) gingivalis. J. Biol. Chem. 267, 18902-18907.

Wright, L. M., Maloney, W., Yu, X., Kindle, L., Collin-Osdoby, P., and Osdoby, P. (2005). Stromal cellderived factor-1 binding to its chemokine receptor CXCR4 on precursor cells promotes the chemotactic recruitment, development and 
survival of human osteoclasts. Bone 36, 840-853.

Wright, S. D., Ramos, R. A., Tobias, P. S., Ulevitch, R. J., and Mathison, J. C. (1990). CD14, a receptor for complexes of lipopolysaccharide (LPS) and LPS binding protein. Science 249, 1431-1433.

Wurfel, M. M., Monks, B. G., Ingalls, R. R., Dedrick, R. L., Delude, R., Zhou, D., Lamping, N., Schumann, R. R., Thieringer, R., Fenton, M. J., Wright, S. D., and Golenbock, D. (1997). Targeted deletion of the lipopolysaccharide (LPS)binding protein gene leads to profound suppression of LPS responses ex vivo, whereas in vivo responses remain intact. J. Exp. Med. 186, 2051-2056.

Yamamoto, M., Sato, S., Hemmi, H., Hoshino, K., Kaisho, T., Sanjo, H., Takeuchi, O., Sugiyama, M., Okabe, M., Takeda, K., and Akira, S. (2003). Role of adaptor TRIF in the MyD88-independent toll-like receptor signaling pathway. Science 301, 640-643.

Yamin, T. T., and Miller, D. K. (1997). The interleukin-1 receptorassociated kinase is degraded by proteasomes following its phosphorylation. J. Biol. Chem. 272, 21540-21547.

Yang, M., Mailhot, G., MacKay, C. A., Mason-Savas, A., Aubin, J., and Odgren, P. R. (2006). Chemokine and chemokine receptor expression during colony stimulating factor-1induced osteoclast differentiation in the toothless osteopetrotic rat: a key role for CCL9 (MIPlgamma) in osteoclastogenesis in vivo and in vitro. Blood 107, 2262-2270.

Yano, S., Mentaverri, R., Kanuparthi, D., Bandyopadhyay, S., Rivera, A., Brown, E. M., and Chattopadhyay, N. (2005). Functional expression of beta-chemokine receptors in osteoblasts: role of regulated upon activation, normal $\mathrm{T}$ cell expressed and secreted (RANTES) in osteoblasts and regulation of its secretion by osteoblasts and osteoclasts. Endocrinology 146, 2324-2335.

Yasuda, H., Shima, N., Nakagawa, N., Mochizuki, S.-I., Yano, K., Fujise, N., Sato, Y., Goto, M., Yamaguchi, K., Kuriyama, M., Kanno, T., Murakami, A., Tsuda, E., Morinaga, T., and Higashio, K. (1998). Identity of osteoclastogenesis inhibitory factor (OCIF) and osteoprotegerin (OPG): a mechanism by which OPG/OCIF inhibits osteoclastogenesis in vitro. Endocrinology 139, 1329-1337.

Yiangou, Y., Facer, P., Dyer, N. H., Chan, C. L., Knowles, C., Williams, N. S., and Anand, P. (2001). Vanilloid receptor 1 immunoreactivity in inflamed human bowel. Lancet 357, 1338-1339.

Yoshimura, T., Matsushima, K., Tanaka, S., Robinson, E. A., Appella, E., Oppenheim, J. J., and Leonard, E. J. (1987). Purification of a human monocyte-derived neutrophil chemotactic factor that has peptide sequence similarity to other host defense cytokines. Proc. Natl. Acad. Sci. U.S.A. 84, 9233-9237.

Yu, X., Huang, Y., Collin-Osdoby, P., and Osdoby, P. (2004). CCR1 chemokines promote the chemotactic recruitment, RANKL development, and motility of osteoclasts and are induced by inflammatory cytokines in osteoblasts. J. Bone Miner. Res. 19, 2065-2077.

Yumoto, H., Nakae, H., Fujinaka, K. Ebisu, S., and Matsuo, T. (1999). Interleukin-6 (IL-6) and IL-8 are induced in human oral epithelial cells in response to exposure to periodontopathic Eikenella corrodens. Infect. Immun. 67 384-394.

Zadeh, H. H., Nichols, F. C., and Miyasaki, K. T. (1999). The role of the cell-mediated immune response to Actinobacillus actinomycetemcomitans and Porphyromonas gingivalis in periodontitis. Periodontol. 2000, 20, 239-288.

Zawawi, K. H., Kantarci, A., SchulzeSpäte, U., Fujita, T., Batista, E. L. Jr., Amar, S., and Van Dyke, T. E. (2010). Moesin-induced signaling in response to lipopolysaccharide in macrophages. J. Periodont. Res. 45, 589-601.

Zlotnik, A., and Yoshie, O. (2000). Chemokines: a new classification system and their role in immunity. Immunity 12, 121-127.
Zurawski, G., and de Vries, J. E. (1994). Interleukin 13, an interleukin 4-like cytokine that acts on monocytes and B cells, but not on T cells. Immunol. Today 15, 19-26.

Zwaka, T. P., Hombach, V., and Torzewski, J. (2001). C-reactive protein-mediated low density lipoprotein uptake by macrophages: implications for atherosclerosis. Circulation 103, 1194-1197.

Conflict of Interest Statement: The authors declare that the research was conducted in the absence of any commercial or financial relationships that could be construed as a potential conflict of interest.

Received: 09 November 2011; paper pending published: 01 February 2012; accepted: 24 April 2012; published online: 16 May 2012.

Citation: Hasturk H, Kantarci A and Van Dyke TE (2012) Oral inflammatory diseases and systemic inflammation: role of the macrophage. Front. Immun. 3:118. doi: 10.3389/fimmu.2012.00118

This article was submitted to Frontiers in Inflammation, a specialty of Frontiers in Immunology.

Copyright (c) 2012 Hasturk, Kantarci and Van Dyke. This is an open-access article distributed under the terms of the Creative Commons Attribution Non Commercial License, which permits noncommercial use, distribution, and reproduction in other forums, provided the original authors and source are credited. 